\title{
Cerámica monocroma esgrafiada/incisa de la Gran Nicoya (siglos I-XVI d.C.)
}

Gilles Desrayaud

\section{OpenEdition}

\section{Journals}

Edición electrónica

URL: https://journals.openedition.org/jsa/1998

DOI: 10.4000/jsa. 1998

ISSN: 1957-7842

Editor

Société des américanistes

\section{Edición impresa}

Fecha de publicación: 1 enero 2001

Paginación: 39-88

ISSN: 0037-9174

\section{Referencia electrónica}

Gilles Desrayaud, «Cerámica monocroma esgrafiada/incisa de la Gran Nicoya (siglos I-xvı d.C.)», Journal de la Société des américanistes [En línea], 87 | 2001, Publicado el 17 noviembre 2005, consultado el 08 junio 2021. URL: http://journals.openedition.org/jsa/1998 ; DOI: https://doi.org/ 10.4000/jsa.1998 


\title{
CERÁMICA MONOCROMA ESGRAFIADA / INCISA DE LA GRAN NICOYA (siglos I-XVI d.C.)
}

\author{
Gilles DESRAYAUD *
}

A fin de profundizar y complementar nuestro conocimiento de la cerámica precolombina de la "Subárea » de Gran Nicoya, conocida sobre todo por sus policromos, se llevó a cabo el estudio icono-morfológico de 326 piezas de tradición monocroma esgrafiada / incisa. Finos modelados figurativos y diseños geométricos adornan recipientes, figurillas e instrumentos de música, confiriéndoles complejos significados simbólicos. Tras un reexamen de la tipología a través de la bibliografía existente, se realizaron seriaciones morfológicas y un análisis iconográfico detallado, junto con comparaciones con cerámicas y artefactos decorados de la misma región y otras cercanas. El cruce de datos iconográficos en relación con la organización espacial del decorado y de las formas funcionales de las piezas permitió demostrar el origen cultural istmeño de esa tradición, centrada en el noroeste de Costa Rica para la Gran Nicoya. También pudo comprobarse la expansión gradual de una fuerte influencia mesoamericana a partir del siglo ix d. C. en Guanacaste, lo cual corrobora las hipótesis etnohistóricas acerca de la llegada de grupos nortenos en la zona.

Palabras Claves : arqueología, Costa Rica, Nicaragua, Gran Nicoya, cerámica.

Greater Nicoya Engraved / Incised Monochrome Ceramics (1 $1^{s t}-16^{t h}$ centuries A.D.).

In order to deepen and complement our knowledge of Precolumbian ceramics from the Greater Nicoya « Subarea », well known for its polychrome paintings, the present study concentrates on the icono-morphological analysis of 326 monochrome engraved / incised vessels and clay objects from museum and private collections. Containers, figurines and musical instruments are decorated with fine figurative modellings and geometrical patterns of complex symbolical significances. After reexamining typology through the available bibliography, we carried out morphological seriations and an iconographic analysis, along with comparisons with ceramics and decorated artefacts from the same and neighbouring areas. The crossing of iconographic data related to the spatial organization of decoration with the functional shapes of vessels and objects helped to demonstrate the Isthmian cultural origins of that tradition, centered on Northwestern Costa Rica as regards Greater Nicoya. It also underlined the gradual expansion of a strong Mesoamerican influence from the $9^{\text {th }}$ century A.D. onwards, corroborating ethnohistorical hypotleses about the arrival of Northeners in the area.

KEY wORDS : archaeology, Costa Rica, Nicaragua, Greater Nicoya, ceramics.

\footnotetext{
Pari

* Centre d'archéologie précolombienne, université đe Paris I Panthéon-Sorbonne, 3, rue Michelet, 75006

Journal de la Société des Américanistes, 2001, 87 : p. 39 à 88. Copyright OSociété des Américanistes.
} 
Céramique monochrome gravée / incisée de la Grande Nicoya (I-XIre siècles apr. J.-C.).

Afin d'approfondir et de compléter nos connaissances sur la céramique précolombienne de la zone de la Grande Nicoya, connue avant tout pour ses polychromes, nous avons procédé à l'analyse d'un corpus de 326 pièces de tradition monochrome gravée / incisée. Ces récipients, figurines et instruments de musique sont décorés de modelages figuratifs et de motifs géométriques élaborés qui leur confèrent une dimension symbolique complexe. Suite à un réexamen de la typologie d'après la bibliogaphie, des sériations morphologiques et une analyse iconographique détaillée ont été réalisées, ainsi que des comparaisons avec les céramiques et objets décorés de la même zone et des régions voisines. Les covariances entre les données iconographiques en relation avec l'organisation spatiale des décors et les formes fonctionnelles des pièces ont permis d'établir l'origine culturelle isthmienne de cette tradition, centrée sur le nord-ouest du Costa Rica en ce qui concerne la Grande Nicoya. L'expansion graduelle d'une forte influence mésoaméricaine à partir du IXe siècle apr. J.-C. a également pu être démontrée, confirmant les hypothèses ethnohistoriques de l'arrivée de groupes septentrionaux dans la région.

Mots clÉs : archéologie, Costa Rica, Nicaragua, Grande Nicoya, céramique.

El concepto de una Subárea específica para la Gran Nicoya fue sugerido por primera vez por Samuel Lothrop bajo el nombre de « Región Pacífica » en su monografía de 1926. A falta de fechas absolutas y de datos sobre la procedencia del material (salvo las excavaciones de Hartman, 1907), sus conclusiones se basaban en la presencia de abundantes cerámicas policromas de inspiración mesoamericana, lo cual ocultó la existencia y diversidad de otras tradiciones. Con base en el trabajo de Lothrop y siguiendo el impulso de las primeras investigaciones tipológico-cronológicas realizadas durante los años 50 y 60 (Baudez y Coe 1962, Norweb 1964, Baudez 1967,...), Albert Norweb creó el término de «Greater Nicoya Subarea » en 1961. Según las definiciones entonces elaboradas, la Gran Nicoya cubre la provincia costarricense de Guanacaste (Sector Sur) y la vertiente pacífica de Nicaragua (Sector Norte : véase Figura 3) ; lo que corresponde más o menos a un territorio ocupado por grupos mesoamericanos chorotegas y nicaraos en tiempos de las primeras entradas españolas a principios del siglo Xvi ${ }^{1}$.

No obstante, hoy en día queda claro que los sectores sur y norte de Gran Nicoya no han tenido evoluciones culturales estrictamente similares ${ }^{2}$. Así, para los períodos más antiguos, algunos investigadores consideran el concepto de Gran Nicoya como mera hipótesis. Por cierto, desde Lothrop, el concepto de Gran Nicoya se apoya en datos etnohistóricos y en la presencia de rasgos mesoamericanos en la cerámica a partir del Policromo Medio (Figura 1, Abel Vidor et alii 1990). Las tradiciones cerámicas anteriores al siglo $\mathrm{x}$ d.C., incluso la policroma " sobre engobe de color salmón », siempre han sido consideradas desde la perspectiva de una Gran Nicoya « mesoamericana ", a pesar de la gran variedad de estilos y de la ubicación particular de esa zona en la frontera sur de Mesoamérica con regiones istmeñas.

El presente trabajo se basa en el estudio de una muestra de piezas museológicas y privadas de tradición cerámica monocroma esgrafiada / incisa, presente principalmente en el noroeste de Costa Rica desde el $\mathrm{I}^{\mathrm{er}}$ siglo d.C. hasta principios del siglo XVI (Figuras 2 y 6$)^{3}$. Uno de los principales intereses del estudio de esta tradición radica 
en su larga existencia, situándose su auge durante la segunda mitad del Bicromo en Zonas (300-500 d.C.) ${ }^{4}$ y prolongándose después junto con tipos policromos. Se caracteriza por un decorado esgrafiado / inciso con relleno blanco, sobre superficie rojiza para los tipos antiguos u oscura a partir del Policromo Medio. Los motivos grabados / incisos geométricos (principalmente triángulos con rayados y guilloches) organizados en bandas o frisos adornan recipientes, figurillas e instrumentos de música de tamaño reducido. La mayoría de las piezas llevan finos modelados figurativos zoomorfos y antropomorfos. Su refinamiento decorativo e iconográfico, su tamaño reducido y su marcada presencia en tumbas y escondites apuntan hacia funciones y usos simbólicos. Los recipientes globulares y altos, siempre con decorado exterior, podían contener sustancias sólidas, fluidas o líquidas como ofrendas y / o manjares. Los tambores, ocarinas, silbatos y maracas podían servir al acompañamiento de ceremonias y las figurillas como «fetiches » o « amuletos».

\section{METODOLOGÍA}

Una muestra de 326 piezas enteras monocromas grabadas / incisas de la Gran Nicoya fue reunida a partir de fotos y dibujos publicados o procedentes del Museo Nacional, del Banco Central y del Instituto Nacional de Seguros de Costa Rica (véanse referencias infra). Las piezas fueron clasificadas, con excepción de 9 «indeterminadas ", de acuerdo con la tipología presentada en el volumen 13 de la revista Vinculos (que acopla variantes decorativas con criterios morfológicos y de fabricación ; Abel Vidor et alii 1990).

El análisis del conjunto de piezas permitió completar y precisar las definiciones de los cinco tipos monocromos esgrafiados / incisos establecidos; permitió también integrar el tipo Huerta esgrafiado en la secuencia (a partir de los datos reunidos por J. Sweeney, 1979 y C. Baudez et alii, 1992). Los principales logros tipológicos fueron el establecimiento de seriaciones morfológicas e iconográficas. También se lograron algunas modificaciones de la distribución geográfica y cronológica de esos tipos cerámicos (Figuras 2, 4, 5, 6, 7 y 8).

El análisis iconográfico consistió en estudiar las representaciones animales, humanas e híbridas, así como sus atributos, vínculos y relaciones. De la misma manera, la iconografia y el estilo de las piezas se compararon con aquellos de otros tipos cerámicos y materiales (piedra, orfebrería,...). Luego, se analizaron las relaciones de los motivos con las formas cerámicas, lo que permitió constituir conjuntos iconomorfológicos que caracterizan los seis tipos estudiados (y un inventario descriptivo completo de las piezas estudiadas). El método icono-morfológico empleado se inspira en la tesis de René Viel sobre la cerámica hondureña Ulua-Yojoa Policroma (1977). Para la cerámica monocroma esgrafiada / incisa, se trató de poner en relación y establecer constantes entre las formas funcionales de las cerámicas y la organización espacial de los motivos iconográficos (Figuras 4 y 5). Por ejemplo, durante la segunda mitad del Policromo Antiguo se privilegian recipientes globulares cerrados figurativos (el cuerpo de la vasija representando el cuerpo del ser figurado), mientras que a partir de 1000 d.C. predominan vasijas altas con decorado figurativo « en friso » sobre el exterior: También permite recalcar asociaciones recurrentes entre motivos iconográficos y formas : 26 de las 35 representaciones de mujer en la muestra estudiada son 
figurillas de tipo Guinea. Las variaciones de organización espacial de las representaciones iconográficas se dividieron en cinco variables : cerámicas zoomorfas, ant ropomorfas, antropo-zoomorfas, con figurilla modelada en el exterior y con representaciones « en friso ». No se tomaron en cuenta los motivos geométricos a causa de su organización constante. Como ordenada de los cuadros icono-morfológicos escogimos los motivos iconográficos figurativos repartidos según las cinco variables espaciales definidas ; en abscisa aparecen las categorías morfológicas funcionales establecidas en las figuras 4 y 5 .

La gran mayoría de las piezas proceden de excavaciones «no-controladas » o antiguas, de fosas o de escondites, que tuvieron fugar en Costa Rica a lo largo del siglo. La escasez de datos contextuales y tafonómicos en la bibliografía disponible impidió llevar más adelante interpretaciones sobre la función y el uso de las distintas categorias de cerámicas estudiadas.

\section{Tipología}

Las siguientes definiciones tipológicas comprenden breves sintesis bibliográficas del estado actual de la investigación de campo publicada sobre la cerámica monocroma grabada / incisa. Han sido modificadas con relación a trabajos anteriores según los nuevos datos obtenidos en el presente estudio (véase stupra). Forman la base sobre la cual se asienta la reflexión antropológica e histórica acerca del material cerámico estudiado. No cabe duda de que esta tipología necesitaría un nuevo examen crítico a partir de tiestos y piezas enteras recogidas in situ, para aclarar los puntos de confusión que existen en la literatura (en particular la confusión entre tipos decorativos y tipos cerámicos cruzando distintas variantes tipo-morfológicas). No obstante, forman una base clasificatoria, cronológica y geográfica suficientemente sólida para cimentar la problemática icono-morfológica desarrollada en este trabajo.

Tipo Guinea esgrafiado : (Figuras 9-12)

Referencias :

- Baudez 1967, pp. 73-79.

- Sweeney 1979, pp. 204-223.

- Abel Vidor et alii 1990 , pp. 68-78.

- Baudez et alii 1992, pp. 133-137.

Muestra : 138 piezas (P1-122, P128, P169[?], P274, P283-284, P304-313, P315).

Criterios diagnósticos y variedades :

- Superficie rojiza engobada y / o pulida.

— Bordes con labio doble en forma de « $\mathrm{Y} »$.

- Líneas « de púas » esgrafiadas en bandas y cruces.

- Soportes mamiformes o cónicos perforados o hendidos.

- Pedestales de paredes ahuecadas.

- Cuencos, tazones y ollas zoomorfos y antropomorfos (Figuras 7 y 8).

- Figurillas femeninas con rasgos faciales « grotescos » (quizá zoomorfos indeterminados, véase pieza $n^{\circ} 177$, Huerta, infra, ¿rasgos de felino ?). 
Variedad Gutiérrez :

- Pasta y acabado burdos.

- Motivos grabados simplificados.

- Superficie anaranjada-marrón de aspecto ceroso.

Variedad Usulután o Resistente :

- Empleo de una de las técnicas norteñas de engobes diferenciados con motivos simples (bandas, puntos, manchas,...) en negativo.

Variedad Bicroma Zonada :

- Uso de engobes diferenciados (rojizo-anaranjado y blanco-amarillo) en zonas. Cronología (Figura 2) : siglos I-VIII d.C. Guinea abarca la segunda mitad del Bicromo en Zonas (var: Bicroma Zonada y Resistente) y el Policromo Antiguo (var: Gutiérrez).

Distribución geográfica (Figura 6) : provincia actual de Guanacaste y vertiente oriental de la cordillera.

Tipo Marbella inciso y punzonado en zonas : (Figura 13)

Referencias :

- Baudez 1967, pp. 102-105.

- Abel Vidor et alii 1990, pp. 105-107.

Muestra : 62 piezas (P123-168, P269, P287-294, P296-298, P314, P316-318).

Criterios diagnósticos y variedades :

- Decorado inciso, punzonado y / o con impresiones de conchas en zonas.

- Ocarinas y silbatos zoomorfos (Figura 8).

Variedad Marbella :

- En general, engobe rojo pulido.

- Impresiones de conchas.

Variedad Corrozal :

- En general, sin engobe.

- Decorado inciso y punteado en zonas.

Cronología (Figura 2) : siglos I-V d.C.

Distribución geográfica (Figura 6) : Península de Nicoya y Valle del Tempisque.

Tipo Belén esgrafiado : (Figura 14)

Referencias :

- Baudez 1967, pp. 125-130.

- Sweeney 1979, pp. 268-272.

- Hoopes 1986, pp. 138-142.

- Abel Vidor et alii 1990, pp. 235-244.

- Baudez et alii 1992, pp. 183-186.

Muestra : 13 piezas (P210-217, P219-220, P271, P285, P326).

Criterios diagnósticos y variedades :

- Superficie sin engobar:

- Soportes huecos mamiformes compuestos. 
- Soportes en forma de cabezas zoomorfas.

— Líneas grabadas múltiples verticales y oblicuas.

- Motivo esgrafiado del « tablero de cuadros".

- Figurillas modeladas en el exterior (Figura $14 \mathrm{~A} / \mathrm{C})^{5}$

Variedad Palmares :

Sus características de acabado burdo y uso casi exclusivo del « tablero de cuadros » parecen poco diagnósticas. No obstante, el número limitado de piezas no permitió examinar la realidad de esta variedad.

Variedad Ayotes :

- Engobe marrón (a veces).

- Bordes con labio en forma de « $\mathrm{T}$ ».

Cronología (Figura 2) : 600-1200 d.C. Caractéristico del Policromo Antiguo y de los dos primeros tercios del Policromo Medio.

Distribución geográfica (Figura 6) : provincia actual de Guanacaste. La variedad Ayotes, definida por J. Hoopes para la Laguna de Arenal, parece limitarse a la cordillera.

Tipo Huerta esgrafiado / inciso : (Figuras 15-17)

Referencias :

- Sweeney 1979, pp. 304-313.

- Baudez et alii 1992, pp. 190-192.

Muestra : 50 piezas (P170-209, P279-281, P319, P325).

Criterios diagnósticos y variedades :

- Superficie engobada y pulida, en general negra.

- Cuellos estrechos compuestos y complejos, modelados y / o grabados / incisos.

- Jarrones y ollas-jarrones figurativos.

- Representaciones figurativas en las paredes exteriores de las vasijas.

- Motivo de « escalones », de la greca escalonada y del guilloche vertical.

Historial : el tipo fue definido por Jeanne W. Sweeney en el 1975 a partir del material excavado por Michael D. Coe en Huerta del Aguacate durante los años 1959-60. Basándose en una colección de tiestos, ella creó tres variedades ("Engraved», "Grooved-rim » y " Plain »). En realidad, esas variedades representan diferentes modalidades decorativas de un solo y único tipo cerámico.

Cronología (Figura 2) : entre los siglos VII / VIII-XIII d.C. Las únicas fechas absolutas y datos secuenciales a disposición fueron obtenidos por M. D. Coe en Huerta del Aguacate. Huerta cubre casi la totalidad del Policromo Medio. Nace durante el Policromo Antiguo y comparte formas y decorados con Belén y tipos pintados antiguos tales como Galo y Carrillo. Está ausente de contextos tardíos.

Distribución geográfica (Figura 6) : parece limitarse al Golfo de Papagayo, al occidente de la Península de Nicoya y al centro-norte del Valle del Tempisque.

Tipo Castillo esgrafiado : (Figura 18)

Referencias :

- Sweeney 1979, pp. 325-328. 
- Healy 1980, pp. 98-104.

—Day 1984, pp. 283-284.

— Gorin 1989, pp. 386-388.

— Abel Vidor et alii 1990, pp. 297-299.

- Baudez et alii 1992, pp. 133-137.

Muestra : 22 piezas (P221-239, P270, P276, P299).

Criterios diagnósticos y variedades :

- Superficie pulida y / o engobada marrón a negra.

- Friso de triángulos con entrecruzado debajo del labio exterior.

— Motivo esgrafiado de la « serpiente emplumada » (Healy 1980, pp. 99-101).

- Aplicados modelados de reptiles.

- Recipientes abiertos de base llana.

Variaciones locales : a finales de los 80 , Ronald L. Bishop y Frederick W. Lange, con la ayuda de otros científicos, efectuaron análisis espectrométricos sobre la composición de las pastas cerámicas de la Gran Nicoya (Bishop et alii 1988 y Bishop et alii 1994). La casi totalidad de las pastas de la muestra de piezas del tipo Castillo procedentes de ambos sectores (Sur y Norte) dieron resultados que vinculaban su composición mineral con yacimientos nicaragüenses. Se sugirió entonces la existencia de centros de producción norteños y de una difusión hacia el sur mediante intercambios. No obstante, esa hipótesis tiene que ser matizada. En efecto, ciertas piezas de Castillo oriundas del sector costarricense son de morfología específica y pertenecen a categorías icono-morfológicas características del noroeste de Costa Rica, pero desconocidas más al norte. Son, por ejemplo, ollas dobles de cuello cóncavo (Figura $18 \mathrm{~A} / \mathrm{B}$ ) emparentadas con el tipo meridional Jicote Policromo (1000-1550 d.C., Sweeney 1979, pp. 610-a), o también pequeños tazones ornitomorfos ${ }^{6}$ parecidos al tipo meridional Altiplano Policromo (1000-1350 d.C., Katz ed. 1985, pp. 134-135). No se puede sostener el postulado del orígen norteño único de Castillo. La procedencia de la materia prima (arcilla y/o desgrasante) no determina en absoluto el lugar de fabricación. La existencia de un estilo norteño y de otro sureño apunta más bien hacia lugares de producción diversificados, cuyos intercambios hasta ahora se desconocen.

Cronología (Figura 2) : 1050-1550 d.C.

Distibución geográfica (Figura 6): Castillo es calificado de «pan-regional». Se encuentra en proporciones variables desde el Lago Nicaragua hasta el Golfo de Nicoya, con excepción de la Cordillera de Guanacaste.

Tipo Murrillo inciso : (Figura 19)

Referencias :

- Baudez 1967, pp. 165-167.

- Lange \& Murray 1977.

- Sweeney 1979, pp. 352-356.

- Day 1984, pp. 306-307.

- Abel Vidor et alii 1990, pp. 314-317.

— Baudez et alii 1992, pp. 210-211. 
Muestra : 31 piezas (P240-266, P300-303).

Criterios diagnósticos y variedades :

- Superficie natural pulida negra o engobada marrón a xojiza.

- Incisiones anchas parálelas oblicuas.

- Pequeños aplicados figurativos modelados toscos.

- Cuellos y labios exteriores compuestos incisos.

Cronología (Figura 2) : 1050-1550 d.C.

Distribución geográfica (Figura 6) : presente en todo el Sector Sur, excepto en la cordillera. Está ausente del Sector Norte, salvo una excepción en la Isla de Ometepe ${ }^{7}$.

\section{ICONOGRAFÍA}

\section{Metodología iconográfica}

Cada pieza fue analizada con el fin de determinar los elementos figurativos (zoomorfos ${ }^{8}$, antropomorfos y atributos culturales) y geométricos (triángulos, guilloche,...) de la decoración. Luego, se analizaron los motivos iconográficos (conjuntos de elementos que forman "semios", emblemas o símbolos). Los motivos pueden ser figurativos (representaciones antropomorfas, zoomorfas, híbridas y de artefactos) o abstractos (cruces, frisos y paneles combinando varios elementos geométricos). A veces, el carácter semántico y / o simbólico de los motivos no es patente ; y algunos motivos quedaron indeterminados. Resulta por ejemplo difícil demostrar el carácter conscientemente simbólico o al contrario "decorativo» de los ubicuos frisos y paneles geométricos.

El estudio de las asociaciones recurrentes entre motivos permite en teoría definir temas iconográficos y acercarse a su significado. Por eso y debido al tamaño no representativo de las muestras estudiadas, los motivos iconográficos de las piezas monocromas grabadas / incisas fueron comparados con aquellos de otros tipos cerámicos (principalmente policromos) y materiales (piedras volcánicas, piedras verdes, hueso, guanín,...), a través de la bibliografia existente.

A continuación, se presentan los principales motivos iconográficos observados en el cuerpo de piezas (véanse ordenadas Figuras 4 y 5). Sus significados y asociaciones principales (temas) fueron evocados con prudencia. La naturaleza fragmentaria de la documentación disponible (muestreo no sistemático, contexto desconocido,...) incrementa todavía más los problemas epistemológicos acerca de la interpretación antropológica de estos restos materiales.

\section{Bestiario $^{9}$}

Muy a menudo las representaciones zoomorfas llevan aderezos humanos (pendientes, colgantes, tocas, ...). No obstante, ese antropomorfismo « sutil » nunca afecta los elementos biológicos, al contrario de las representaciones claramente antropozoomorfas (véase infra). En ocasiones, el mismo cuerpo lleva otra cabeza en el lugar de la cola. Esa variante estilística (cuyo sentido todavía se nos escapa) no parece estar relacionada con las representaciones teratológicas de bicefalismo ${ }^{10}$. 


\section{Batracios (Figuras $10 \mathrm{I}, 13 \mathrm{E}, 16 \mathrm{H}, 19 \mathrm{~F}[\mathrm{iz}]$.}

Piezas de Marbella representan sapos (Bufo Marinus) reconocibles por las glándulas que llevan en las sienes y su cresta interorbital. Se encuentran representaciones de sapos y ranas en conjuntos contemporáneos de Marbella ${ }^{11}$. Existe una continuación de ese motivo figurativo hasta el Contacto, por lo menos en Guanacaste ${ }^{12}$.

Reptiles (cocodrilos, iguanas y serpientes,... Figuras 9 B, 10 H y J, 15 E, 16 F, 18 C)

A veces, las representaciones de esas tres categorías animales comparten elementos iconográficos similares, tales como el morro saledizo (en forma de bulto, cilindro o voluta), una lengua serpentina y crestas sagitales y guturales. Aparentemente, iban asociados en el mismo conjunto semántico. Así, se encuentran representaciones de reptiles bastante específicas junto con otras híbridas o indeterminadas. También parece que esos tres reptiles eran complementarios y / o intercambiables en numerosos casos de asociaciones iconográficas (véase Soto Méndez 1996, pp. 99). Esos reptiles se encuentran en tipos cerámicos bicromos, tricromos y policromos y en objetos de piedra verde sincrónicos con Guinea ${ }^{13}$. Códigos iconográficos similares siguen en existencia para los otros tipos monocromos grabados / incisos, por lo menos en parte, hasta el Contacto.

\section{Tortugas (Figuras $9 \mathrm{~A}, 13 \mathrm{H}$ )}

El elemento figurativo principal de las representaciones de tortugas es el caparazón (casi siempre bipartito elipsoide) del cual sale la cabeza y a veces la cola. En la "Gran Nicoya », las representaciones de tortugas parecen ser escasas y mayoritariamente del tipo Guinea ${ }^{14}$.

\section{Pecarís y sahinos (Figura 9 D)}

Los iconos de pecaríes se caracterizan por un hocico porcino (que no debe confundirse con el morro en forma de tubo del tapir ${ }^{15}$ ), colmillos saledizos, ojos en forma de almendra, orejas redondas, a veces « crestas » sagitales y una fina voluta alargada o línea en el pescuezo. Es probable que las volutas marcando el pescuezo representen el «collar» blanco del sahino (véase Benson ed. 1981 Figura 61). En Guanacaste, las imágenes de pecaríes parecen limitarse al Bicromo en Zonas (500 a.C. -500 d.C.) ${ }^{16}$.

\section{Felinos (Figuras $10 \mathrm{~B}, 13 \mathrm{~A}, 14 \mathrm{D}, 15 \mathrm{C} / \mathrm{D}, 16 \mathrm{~A}, \mathrm{~B}$ y D)}

Los felinos se caracterizan por belfos con bigotes, orejas redondas, un morro corto, ojos almendrados y a veces rayas y puntos en la cabeza y el cuerpo (felinos moteados). El motivo del felino, minoritario para los períodos antiguos (algunos ejemplares de Guinea y de Marbella), se generaliza a partir del Policromo Medio, en especial los felinos moteados de iconografia mesoamericana para los tipos policromos ${ }^{17}$. Es posible que, de cierto modo, las diferencias biológicas de tamaño y peligrosidad para el hombre entre las especies de felinos de la región hayan sido consideradas en la iconografía cerámica. De hecho, las representaciones de felinos agresivos moteados con «mariposas» (círculos multiples o conteniendo varios puntos en el pelaje) corresponden más bien al jaguar (Felis onca, véanse Figuras 15 D, 16 B y D), y las imágenes de «tigrillos» (que se parecen más a gatos que a "tigres», véase 
Figura 15 C) al margay o al ocelote (Felis wiedii y Felis pardalis). En todo caso, los felinos, moteados o no, adoptan dos posturas opuestas : una agresiva y de predación ${ }^{18}$ y otra de « gato » amansado.

Perros y coyotes (Figuras $10 \mathrm{~F}$ )

Se destacan por un morro alargado, dientes puntiagudos, orejas y un cráneo redondos. Las representaciones de cánidos son escasas, tanto en la cerámica como en otros materiales ${ }^{19}$.

Armadillos (Figuras 13 F, G y K)

Varias piezas de Marbella representan armadillos, caracterizados por su caparazón escamoso y / o compuesto por líneas verticales, una cabeza alargada y una colita. El motivo del armadillo se encuentra desde el Bicromo en Zonas hasta el Contacto.

\section{Monos (Figura 9 E)}

Se caracterizan por su larga cola enrollada, rasgos « humanoides » y rostro destacado del resto del pelaje. Es un motivo bastante común desde el Bicromo en Zonas hasta principios del Policromo Tardío ${ }^{20}$.

Venado (Figura $10 \mathrm{G}$ )

La pieza $n^{\circ} 38$ parece ser la única representación de ciervo publicada para la "Gran Nicoya " ${ }^{21}$. Se trata de un Odocoileus virginianus reconocible por sus pezuñas hendidas, morro chato, cornamenta y colita encorvada sobre la grupa (postura de "fuga »). Aparentemente, esa especie constituía una de las principales fuentes de carne de caza en tiempos precolombinos (Oviedo 1959, vol. I, cap. XIX, Sweeney 1979, pp. 451-468, Healy 1980).

\section{Murciélagos (Figuras 10 C, 13 I, 15 B[centro])}

A pesar de su importancia en el bestiario de la región de Guanacaste para el Bicromo en Zonas y el Policromo Antiguo, existen pocas representaciones emblemáticas del murciélago ${ }^{22}$, pero, a la inversa, muchas de híbridos o personajes antropozoomorfos con elementos de quiróptero (véase $i n f r a$ ). Los elementos característicos del murciélago son una silueta y cabeza de mamífero asociadas con alas y / o miembros superiores doblados y / o en posición de vuelo y a veces ojos rectangulares y un morro abultado (que, para los híbridos, se puede confundir con aquel de los reptiles).

\section{Aves y pájaros}

Son facilmente identificados por sus alas, cola y pico. Además de pájaros indeterminados (Figuras 9 C, 13 B, C y D), se encuentran iconos específicos : rapaces nocturnos ${ }^{23}$, destacados por sus caras planas, grandes ojos y moños en forma de orejas ; rapaces diurnos ${ }^{24}$, reconocibles por su pico encorvado, garras, ojos redondos en cada lado del cráneo y a veces moño en la coronilla ; buitres ${ }^{25}$ (Figuras $10 \mathrm{E}, 14 \mathrm{E}$ ) caracterizados por una cabeza redonda y desplumada, un largo cuello y gran pico abultado; y pelicanos (Figura 10 A y véase Stone 1977, pp. 66 Figura 89), cuyos rasgos son facilmente identificables. 


\section{Animales hibridos y asociaciones de animales}

\section{Reptil alado (Figuras $9 \mathrm{~F}$ )}

La pieza $n^{\circ} 33^{26}$ del tipo Guinea representa un híbrido con cabeza de reptil, alas y cola de ave. La asociación entre ave y reptil es bastante común en todo el Istmo, en particular para figurinas antropo-zoomorfas (véase infra). No parece estar relacionada con el parecido motivo mesoamericano del "monstruo terrestre» que se encuentra en cerámicas más tardías ${ }^{27}$.

Jaguar / cocodrilo

Con la llegada de motivos y temas mesoamericanos a partir del Policromo Medio se generalizan los motivos de felino y cocodrilo. La pieza $\mathrm{n}^{\circ} 319^{28}$ lleva en sus paredes exteriores dos imágenes grabadas de jaguar y cocodrilo.

Murciélago / reptil / ave rapaz (Figura 15 B)

La pieza $n^{\circ} 209$ figura un murciélago asociado con garras de ave rapaz y cuyas alas se prolongan en cabezas de reptil. Tales asociaciones ave/ reptil (véase supra) y murciélago / reptil (véanse motivos antropo-zoomorfos infra) son comunes en el Istmo en general y en especial antes del Policromo Medio para la « Gran Nicoya » 29.

\section{Representaciones antropomorfas}

Femeninas (Figuras 11 A y F, 17 E, 19 A y D)

Además de los elementos somáticos evidentes (senos, vulva, embarazo ${ }^{30}, \ldots$ ) se destacan a veces por un ombligo hinchado, el llevar vasijas o a una criatura y tener una postura característica : piernas abiertas y manos colocadas en el pecho, el vientre o las caderas, sentadas sobre un banquito o "metate ", en cuclillas o de pie. Se destaca también el caso de la pieza ${ }^{\circ} 86$ que figura a una mujer moliendo sobre un metate con una mano cilíndrica ${ }^{31}$. Muy a menudo, las figurillas del tipo Guinea tienen un rostro « grotesco » con ojos globulares y una boca enseñando una dentadura maciza. Todas esas mujeres llevan una toca (generalmente decorada y ovalada en forma de plato), a veces una especie de faja en las caderas, un tapa-rabo, bolainas y / o brazaletes en las muñecas y tobillos. Muchas de ellas exhiben motivos geométricos en distintas partes del cuerpo : en la cara, los hombros, los senos, el vientre y / o las piernas. Esos diseños pueden representar detalles de la vestimenta, adornos ${ }^{32}$ y probablemente pinturas corporales y/o tatuajes decorativos, pero también motivos complejos simbólicos (cruces y bandas verticales) en el busto, en particular sobre el vientre. Existen representaciones y figurillas femeninas cerámicas similares durante todo el primer milenio después de Cristo, desde el Bicromo en Zonas hasta mediados del Policromo Medio ${ }^{33}$. A finales del Policromo Medio se vuelven escasas y más estilizadas, señaladamente con la técnica del moldaje (Ferrero 1987, pp. 228).

\section{Masculinas (Figuras 11 D y G)}

A la inversa de los antropomorfos femeninos, los iconos de varones son mucho menos abundantes en detrimento de los antropo-zoomorfos masculinos. Además del pene y de los testículos, la virilidad puede expresarse por una postura característica : 
acurrucado sobre una rodilla, teniendo la otra pierna levantada con un « pie en tierra " y por lo menos una mano sobre el ingle o el muslo ${ }^{34}$. Todos los hombres llevan tocas o sombreros (rectangulares, cónicos, en forma de casco,...), a veces túnicas, adornos y decoraciones similares a los que llevan las mujeres (como pendientes cónicos por ejemplo, de los cuales se excavaron ejemplares originales de cobre en el sitio Filadelfia, Ferrero 1987, p. 120). Al igual que los antropomorfos femeninos, los masculinos modelados de « estilo Guinea » escasean a partir del Policromo Medio, dejando lugar a representaciones pintadas de iconografia mesoamericana.

¿Un hermafrodita ? (Figura $11 \mathrm{~B}$ )

La pieza $n^{\circ} 71^{35}$ de iconografía similar a las figurinas femeninas posee a la vez atributos sexuales femeninos (pechos) y masculinos (pene y testículos). Es ahora imposible determinar si se trata de una representación teratológica y / o simbólica.

Hombre y mujer, parejas (Fig. 11 F, G e I)

Se encuentran cerámicas aparejadas tanto a nivel estilístico como contextual ${ }^{36}$. El caso más frecuente consta de una paridad varón / hembra, en particular de una pareja antropomorfa. Se destacan ejemplares más singulares, como una mujer cargando a un hombre con un sólo brazo, al igual que acróbatas, o una representación de coito ${ }^{37}$. Aparentemente, esas representaciones paritarias desaparecen a mediados del Policromo Medio.

Atributos humanos

Los antropomorfos (y por ende antropo-zoomorfos) pueden caracterizarse por atributos físicos, comportamentales y/o materiales, independientemente de su género.

- Deformidades ( ${ }^{\mathrm{er}}$ milenio d.C. ; Figura $\left.11 \mathrm{I}\right)$

Numerosos antropomorfos tienen chepas y/o abultamientos en el busto o la cabeza. Parecen ser elementos teratológicos, cuyo simbolismo se desconoce. Existen ejemplares de Tola Tricromo, Rosales, monocromos « Red Ware », Galo y Carrillo ${ }^{38}$.

- Postura de descanso ( $\mathrm{I}^{\mathrm{er}}$ milenio d.C. hasta mediados del Policromo Medio ; Figuras 11 D, F y G)

A veces, se representa a hombres y mujeres tendidos de espalda o recostados de lado, generalmente sosteniendo su cabeza con la mano. La misma postura ocurre para la pieza $n^{\circ} 58$ donde está representada una mujer con una criatura acostadas en una hamaca. Existen piezas similares policromas ${ }^{39}$.

- Banquillos, « metates » ( ${ }^{\text {er }}$ milenio d.C. ; Figuras 12 A y F)

Muchas piezas figuran a un personaje sentado en un banquillo o «metate», generalmente zoomorfo (aves rapaces, reptiles, felinos,...) y muy parecido a los « metates » de piedra encontrados en tumbas de la misma época. Puesto que en esos banquillos se pudo colocar tanto a una mujer meciendo a su criatura como a un guerrero con escudo, su supuesta identificación como tronos de poder o de cacique tendría que volver a examinarse más detenida y críticamente ${ }^{40}$.

— «Alter-ego » (Figuras $11 \mathrm{H}, 12 \mathrm{~F}$, ¿15 E ?)

A menudo, los personajes llevan una o varias representaciones animales en lo alto de la cabeza. Este motivo iconográfico se hizo famoso en la «Gran Nicoya » con las 
primeras publicaciones de estatuas monumentales de piedra de las islas del Lago Nicaragua por Ephraim Squier, en 1852, y Karl Bovallius en 1886 (véase Lothrop 1926, vol. I, lám. IV-V). Según la hipótesis de que eran representaciones de animales « fetiches » o « gemelos », se les llamó « alter-ego ». Ese motivo ocurre a lo largo del primer milenio d.C. ${ }^{41}$. Existen motivos muy similares en toda la cuenca del Caribe, por lo menos desde las Antillas y Venezuela ("adornos múltiples ») hasta distintas zonas de Mesoamérica (« nahuales »).

\section{Cefalomorfos}

- Cabezas « cadavéricas » ( $\mathrm{I}^{\mathrm{er}}$ milenio d.C. ; Figuras $11 \mathrm{C}$ y $\left.17 \mathrm{~A}\right)$

Durante el $\mathrm{I}^{\mathrm{er}}$ milenio d.C., son frecuentes las representaciones realistas de cabezas antropomorfas. A veces estas cabezas exhiben síntomas postmortem (encías descarnadas, ojos hinchados u órbitas huecas, a veces sin globos oculares, mejillas ahuecadas 42 y / o mandíbulas emaciadas). También se encuentran representaciones de calaveras. Esa evocación de la muerte se encuentra tanto en ollas globulares con motivos geométricos complejos, de Guinea, Huerta, Tola, Galo y Carrillo, como en mazos de piedra $^{43}$.

- Caras esquemáticas (¿800 ?-1550 d.C. ; Figuras 17 B y 18 B)

A partir del Policromo Medio aparecen representaciones esquemáticas de caras antropomorfas o antropo-zoomorfas ${ }^{44}$. Según Diana Leibsohn (1988) esas « cabezas efigies » serían simplificaciones de las cabezas realistas de los períodos anteriores. La ausencia de rasgos mórbidos y motivos geométricos complejos (en particular cruces), así como la presencia de rasgos zoomorfos, me lleva a pensar, al igual que Valéric Lauthelin (com. pers.), que se trata de dos tradiciones distintas : la primera, durante el $1^{\text {er }}$ milenio d.C. en Guanacaste, asocia realismo, muerte y motivos abstractos simbólicos, mientras que la segunda, posteriormente presente en toda la Gran Nicoya, se basa en una iconografia de influencia más bien mesoamericana (Day 1984, cap. IV \& V).

- Ocarina Marbella (Figuras $13 \mathrm{~J}$ )

Una ocarina de dos lóbulos del tipo Marbella (P45), lleva una cara humana modelada en la embocadura ${ }^{45}$.

- « Caras Castillo » (Figuras $18 \mathrm{H}$ )

Tazones del tipo Castillo, procedentes de la Isla de Ometepe, llevan caras (a veces cara y brazos) antropomorfas realistas modeladas en las paredes 46 .

\section{Representaciones antropo-zoomorfas}

Numerosas representaciones combinan elementos antropomorfos y zoomorfos (cuerpo humano con cabeza animal y viceversa, así como elementos zoomorfos en rostros humanos).

\section{Humano / sapo ( ${ }^{\mathrm{er}}$ milenio d.C.)}

Se encuentran sapos antropomorfizados y hombres con glándulas parotoides de batracio ${ }^{47}$.

« Hombre-cocodrilo » (Figura 15 E)

Varias piezas del tipo Huerta representan a un hombre con cabeza de cocodrilo. Este motivo se encuentra desde el Bicromo en Zonas hasta (quizás) finales del 
Policromo Medio ${ }^{48}$. Generalmente, para tipos antiguos como Guinea o Tola, se asocia además con rasgos de quiróptero (véase infra).

Humano / reptil (I ${ }^{\mathrm{er}}$ milenio d.C. ; Figura $\left.12 \mathrm{G}\right)$

Son también comunes las asociaciones entre elementos antropomorfos biológicos y de reptil indeterminado ${ }^{49}$.

Humano / ave ( $\mathrm{I}^{\mathrm{er}}$ milenio d.C. ; Figura $14 \mathrm{~A}$ )

Existen personajes con cuerpo antropomofo y cabeza de ave, de Marbella y Belén $^{50}$.

«Personajes-voladores » (Figuras $12 \mathrm{~A}-\mathrm{F}, 14 \mathrm{~F}, 17 \mathrm{C}$ y D)

Ciertas representaciones figuran a personajes con alas y/o brazos abiertos y doblados, evocando una postura de vuelo, a la manera de alas de murciélago (véase supra). En general, se componen de un cuerpo antropomorfo y de una cabeza zoomorfa de reptil (en especial de cocodrilo), de murciélago, de ave rapaz o de felino. En piezas de Huerta, existen también felinos más o menos antropomorfizados que adoptan la misma postura ${ }^{51}$. La mayoría de esos personajes llevan prendas y atavíos elaborados y a veces motivos geométricos complejos en el vientre. Pueden ser varones o hembras ${ }^{52}$. Están representados « de pie » o sentados en un « metate », a veces con instrumentos de música (maracas y/o flauta), y a menudo llevan uno o varios «alter-ego ». Se encuentran " personajes-voladores» desde el Bicromo en Zonas hasta (quizás) mediados del Policromo Medio ${ }^{53}$. La noción de vuelo simbólico o « místico » es común en las prácticas shamanísticas (para Costa Rica véase Reynoard Baumgarten 1996, pp. 137-161). Ahora bién, la simbología de esas representaciones y su interpretación contextual aún se nos escapan.

\section{Humano / Felino}

A partir del Policromo Medio se encuentran muchas asociaciones entre elementos humanos y felinos (tipo Huerta: felino con cabeza de hombre, Figura $16 \mathrm{C}$; Figura $16 \mathrm{E}$ : mujer[?] con belfos de felino).

\section{Motivos geométricos complejos}

Sin hablar de los elementos y motivos geométricos básicos (véase supra), existen motivos complejos tales como cruces, frisos o emblemas (Figura 15 A). Puede que algunos de ellos sean representaciones de pendientes, collares o pectorales (Figuras $10 \mathrm{~A} \mathrm{y} 17 \mathrm{~F}$ ) ${ }^{54}$. Los otros se emplean a la manera de " glifos » y símbolos abstractos (véase Carlsen 1988).

\section{Cruces y frisos verticales (Figuras $11 \mathrm{~A}, \mathrm{~B}$ e I, $12 \mathrm{~A}-\mathrm{C}, 15 \mathrm{E}$ )}

Estos motivos se encuentran en el busto de personajes antropomorfos y antropozoomorfos, vientre, pechos y sexo de mujeres, ollas cefalomorfas realistas mórbidas, representaciones fálicas o figurando el morro de un cocodrilo (Lothrop 1926, vol. I, pp. 175, Figura 72-d). La aparente asociación semántica a través de tales motivos geométricos entre los órganos genitales de ambos sexos y cabezas cadavéricas apunta hacia la evocación de un vínculo entre la fertilidad y la vida (presente y por venir) y la 
muerte (quizá cabezas efigies de ancestros). Las referencias a distintos animales emblemáticos no es de sorprender dentro de tal contexto. No obstante, se necesitará un muestreo iconográfico y contextual mucho más amplio para desarrollar interpretaciones de ese tipo (tal vez de linaje o de descendencia mitológica). Esos motivos simbólicos se encuentran a lo largo del primer milenio después de Cristo hasta mediados del Policromo Medio en toda la provincia de Guanacaste ${ }^{56}$.

\section{TRADICIONES ISTMEÑA Y MESOAMERICANA}

\section{Tradición istmeña}

Tipológicamente, la tradición monocroma esgrafiada/incisa del noroeste de Costa Rica y el Castillo nicaraguense se emparentan con tipos coetáneos del Valle Central Costarricense y de la Gran Chiriquí (véanse Lothrop 1926, vol. II, Baudez et alii 1993). Existen semejanzas evidentes en el empleo de los motivos y en la estructura de los decorados geométricos grabados / incisos y / o modelados. Aparentemente, esas regiones también comparten categorías icono-morfológicas, lo que supone cierto grado de integración en una misma dinámica regional.

Además, comparaciones sumarias de los motivos y asociaciones iconográficos del noroeste de Costa Rica con aquellos de regiones vecinas istmeñas permitieron constatar similitudes patentes. Comparten los motivos del « hombre-reptil » y / o « hombre cocodrilo ${ }^{56}{ }$, de los « personajes-voladores ${ }^{57}$ » y del « alter-ego ${ }^{58}$ ». Se encuentran también figurillas femeninas similares, personajes de ambos sexos sentados en " metates », cabezas " cadavéricas » y animales emblemáticos parecidos (batracios, reptiles, felinos, aves rapaces, ...) ${ }^{59}$. Casi todos los motivos iconográficos presentes en el Sector Sur de la "Gran Nicoya » durante el $\mathrm{I}^{\mathrm{er}}$ milenio d.C. tienen paralelos desde el centro de Costa Rica hasta el norte de Colombia y oeste de Venezuela, hasta comienzos de la Conquista. Fuera de la cerámica, existen otros rasgos materiales parecidos, tales como « metates » zoomorfos de piedra y estilos de orfebrería (véanse Fonseca Zamora 1994, Bray 1981 y 1984, ...).

Así, una afiliación cultural parece unir todas la regiones del Istmo Americano. Según trabajos arqueológicos y lingüísticos recientes (Constenla Umaña 1994 y Fonseca Zamora 1994), antes de la llegada de grupos mesoamericanos a partir del siglo ix d.C., el noroeste de Costa Rica estaba poblado por grupos de lengua chibcha o misumalpa emparentados con los grupos de « cultura istmeña » esparcidos desde el este de Honduras hasta el norte de Colombia y oeste de Venezuela.

En fin, parece obvio que la tradición monocroma esgrafiada / incisa de la « Gran Nicoya » traduce una herencia cultural istmeña (llamada " chibchoide » por Fonseca Zamora 1994) tanto tipológico como icono-morfológicamente, integrando más tarde elementos mesoamericanos. Esta tradicíon parece ser ampliamente mayoritaria en el noroeste de Costa Rica desde la segunda mitad del Bicromo en Zonas hasta principios del Policromo Medio (siglos I-VIII d.C.). Los escasos objetos mesoamericanos aislados encontrados en contextos de estos períodos evocan más bien intercambios a larga distancia que cualquier influencia cultural ${ }^{60}$. 


\section{Influencia mesoamericana ${ }^{61}$}

A partir del siglo Ix d.C., surgen nuevos motivos y asociaciones de motivos iconográficos con la aparición de los primeros policromos « sobre engobe crema " (en particular el Papagayo). Estos nuevos iconos (alacranes, colibris, cangrejos, pavos, " serpientes emplumadas », " hombre y jaguar», " monstruos terrestres », máscaras antropo-zoomorfas estilizadas,... véase Day 1984, cap. IV-V) se diferencian claramente de la iconografía istmeña, siendo mayoritariamente de tradición mesoamericana (salvo quizá cangrejos y escorpiones que se encuentran también en pendientes de tumbaga en el Diquís y Panamá : véanse Bray 1981 y 1984 y Ferrero 1987).

Así, el Policromo Medio (800-1350 d.C.) en el Sector Sur se caracteriza por una iconografía que mezcla motivos de ambas tradiciones. Huerta, por ejemplo, retoma motivos de Guinea y adopta temas nuevos como felinos antropomorfizados, caras estilizadas y cangrejos (véanse supra y com. pers. V. Lauthelin). A partir del siglo XII d.C., los motivos istmeños desaparecen casi totalmente en la cerámica decorada (con particular excepción de Murrillo). El influjo mesoamericano y la decadencia cualitativa y cuantitativa de los monocromos grabados / incisos, a pesar de su asimilación, son patentes para Castillo, que copia toscamente el estilo de cerámicas policromas tardías.

La influencia mesoamericana a partir del siglo IX d.C. resultó probablemente de la llegada de poblaciones norteñas. Especialistas, etnohistoriadores, linguistas y arqueólogos (véase nota 56), han sugerido que la primera oleada de migrantes pudo ser compuesta por grupos de lengua oto-mangue (antepasados quizás de los chorotegas del Contacto); seguida alrededor del 1200 d.C. por otra de grupos pipil-nicarao de lengua nahua (cuyo viaje quedó en la memoria mítica de sus descendientes para contárselo a los conquistadores y cronistas del siglo XVI; Oviedo 1959, vol. I, cap. XIX). Los primeros recién llegados se habrían instalado en primer lugar en la vertiente pacífica de Nicaragua, fabricando entonces cerámicas policromas « sobre engobe crema » y exportándolas hacia Guanacaste (véanse análisis fisicoquímicos en Bishop 1994). A continuación, la migracíon de grupos nahuat (que posiblemente llegaron hasta el Panamá central), les habría obligado a ocupar parte del noroeste de Costa Rica. Así, entre los siglos XII y XVI grupos «chorotegas » y « nicaraos» se habrían apoderado de buena parte del territorio noroccidental costarriqueño, asimilando y / o rechazando grupos locales. En tiempos de las primeras entradas europeas (entre 1522 y 1550), grupos chorotegas poblaban la región de Granada en Nicaragua, las costas del Golfo de Papagayo, la Península de Nicoya (salvo su extremidad) y el valle costanero del Río Barranca. Los nicaraos ocupaban el Istmo de Rivas y el norte del Valle del Tempisque; mientras que grupos de lengua chibcha o misumalpa, los corobicís, poblaban su parte meridional, el delta y parte de las islas (Oviedo 1959, lám. IX, Constenla Umaña 1994).

Eso explicaría la omnipresencia de motivos mesoamericanos, la decadencia de tradiciones cerámicas locales (monocroma grabada / incisa y « sobre engobe de color salmón ") y motivos iconográficos istmeños a partir del siglo XIII, así como la presencia de una influencia meridional minoritaria. De hecho, a principios del siglo XVI, el cronista español Fernández de Oviedo y Valdés habla de una cerámica negra y pulida, « muy bien labrada », producida en territorio corobicí, en la isla de Chira (Oviedo 
1959, libro. XLII, cap. XII, pp. 424). La descripcíon de Oviedo corresponde muy probablemente al tipo Murrillo, muy abundante en la isla de Chira, cuya tipología e icono-morfología retoman canones istmeños (en especial de la Gran Chiriquí).

\section{CONCLUSIÓN}

Considerando la zona arqueológica de la Gran Nicoya, la tradición cerámica monocroma esgrafiada / incisa apareció como procedente del noroeste costarricense (al igual que la tradición policroma " sobre engobe de color salmón »), que de hecho se desmarca claramente del sector nicaraguense. Los resultados logrados fortalecen la hipótesis de un sector arqueológico sureño aparte, de afiliación istmeña, desmarcándose en la línea de contacto entre la Periferie Sur de Mesoamérica y la zona del Istmo («Area intermediaria » « Area chibchoide »). El desarrollo de ese sector precede de por lo menos un milenio el establecimiento de los rasgos materiales e iconográficos que caracterizan la probable llegada de grupos mesoamericanos a partir del siglo Ix d.C.

Durante el primer milenio d.C., la evolución de la tradición monocroma esgrafiada / incisa de Guanacaste se singulariza por rasgos tipológicos, iconográficos y morfológicos emparentados con las demás culturas de Costa Rica y las de Panamá (y de una manera más general de todas las regiones de la América Central meridional y de la extremidad noroccidental de América del Sur). Durante el Policromo Medio (800-1350 d.C.), a esos rasgos istmeños van añadiéndose, para luego suplantarlos en gran medida, rasgos mesoamericanos. La diversidad y diversificación de los tipos monocromos grabados / incisos, tanto tipo-morfológico como icono-morfológicamente, se explican probablemente en gran parte por el encuentro de esas dos tradiciones culturales distintas. Eso explica además la relativa decadencia cuantativa y cualitativa de la cerámica monocroma esgrafiada/incisa en el noroeste costarricense, mientras estaba floreciente en el Valle Central y el Diquís. Ya no correspondía, o cada vez menos (a pesar de una supervivencia activa ilustrada por los tipos Castillo y Murrillo), a los canones de una « Gran Nicoya mesoamericanizada ».

Los mundos ideológicos ilustrados y simbolizados en las piezas analizadas siguen siendo poco accesibles. La tradición istmeña parece privilegiar la visión de un universo " animista » o "shamanístico » (véase Reynoard Baumgarten 1996). La tradición mesoamericana aparece más codificada, privilegiando una visión más conceptualizada y organizada alrededor de símbolos y / o principios fundamentales (véase Day 1984).

Comparaciones más exhaustivas, en particular con los tipos policromos, permitirán quizás recalcar fenómenos de asimilación, "mestizaje » y / o aculturación, ya perceptibles para ciertos tipos cerámicos como Huerta o Castillo. Entonces, el noroeste de Costa Rica podría llegar a ser uno de los puntos claves para la comprensión de las relaciones entres poblaciones istmeñas y mesoamericanas.

* Manuscrit rȩ́u en janvier 2001, accepté pour publication en mai 2001. 


\section{ANEXO I \\ REFERENCIAS DE LAS PIEZAS POR COLECCIONES \\ $P$ (pieza cerámica) $+n^{\circ}$ atribuido para su estudio \\ (+ referencias de inventario museológico) ${ }^{62}$}

American Museum of Natural History ${ }^{63}$, Washington D.C., E.E.U.U : P64, P67, P88, P274. Banco Nacional de Costa Rica ${ }^{64}$, San José : P18, P59, P183 (0097), P184 (0031), P245 (168), P246 (137), P310 (1580).

British Museum $^{65}$, Londres, R.U : P229, P232, P251.

Carnegie Museum $^{66}$, Pittsburgh, Pennsylvania, E.E.U.U : P42, P43, P126, P127, P128, P129, P143, P218 (2793 105), P273 (2793 111), P289 (2793 106).

Colección Acosta ${ }^{67}$, Costa Rica : P113, P283.

Colección Anderson ${ }^{68}$, E.E.U.U : P79, P98, P204, P286.

Colección Balser ${ }^{69}$, San José, Costa Rica : P89.

Colección Barbier-Mueller ${ }^{70}$, Ginebra, Suiza : P90, P209 (521-36).

Colección Calvo Fallas ${ }^{71}$, Costa Rica : P38.

Colección Dada, Ligia ${ }^{72}$, Bahía de Culebra, Costa Rica : P170, P319 (130), P321 (131), P322 (132), P325 (168).

Colección Gamboa, P. ${ }^{73}$, San José, Costa Rica : P285.

Colección Gillén ${ }^{74}$, Guanacaste, Costa Rica : P222, P241, P242, P243.

Colección Góngora, U. ${ }^{75}$, San José, Costa Rica : P93.

Colección Herrera, M. ${ }^{76}$, San José, Costa Rica : P91.

Coleccion indeterminada: Squier 1853: P3, P65, P66; Lines 1936: P225; Baudez 1967 : P58 ; Baudez 1970 (col. priv., San José) : P201 ; Lange 1976 : P240 ; Stone 1976 : P51, P211 ; Stone 1977 : P2, P15, P61, P62, P63, P73, P80, P82, P102, P266 ; Ferrero 1987 : P10 ; « 126 Auktion... » 1988 : P68, P78 ; Sweeney 1979 : P70, P165, P207, P216, P239, P255, P256, P257, P258, P259, P260 ; Guerrero M. 1986 : P166, P167, P168, P169 ; Abel Vidor et alii 1990 : P9, P60, P97, P152, P174, P214, P217, P250 ; "Trésors du Nouveau Monde » 1992 : P27 ; Lange 1993 : P81 ; Col. privada, Costa Rica (com. pers. Borgnino / Lauthelin) : P100.

Colección Jiménez de la Guardia ${ }^{77}$, San José, Costa Rica : P197.

Colección Jiménez de Roy ${ }^{78}$, Costa Rica : P19, P120, P264.

Colección Margarita de Ruenes ${ }^{79}$, Molinos de Costa Rica : P304, P305.

Colección Oduber ${ }^{80}$, Costa Rica : P33, P306, P307, P312, P315, P316/317, P318, P324.

Colección Paéz, Hernán ${ }^{81}$, Filadelfia, Costa Rica : P101, P308, P309, P314 (124), P320 (95).

Colección Paéz, U. \& S. ${ }^{82}$, Costa Rica : P121, P122, P154.

Colección Robelo, Alfonso ${ }^{83}$, Nicaragua : P313.

Colección Sackler, Arthur ${ }^{84}$, Washington D.C., E.E.U.U : P14, P28, P34, P40, P41, P48, P75, P76, P178, P179, P185, P192, P194 (1117), P202, P212 (N-1058), P220, P263 (N-1149), P265 (N-1094), P270, P281 (N-886).

Denver Art Mfuseum ${ }^{85}$, Colorado, E.E.U.U : P11.

Instituto Nacional de Seguros, Museo del Jade ${ }^{86}$, San José, Costa Rica : P12 (4870), P49, P99, P1 15 (2794), P119, P180, P181, P188, P193 (300), P196 (4037), P249, P261, P267, P268, P279, P290 (4993), P311 (3294).

Museo de América ${ }^{87}$, Madrid, España : P71, P72.

Musée de l'Homme ${ }^{88}$, París, Francia : P4, P6, P7, P44, P45, P46, P53, P54, P55, P104, P105, P107, P108, P110, P111, P145, P146, P156, P157, P158, P210, P219, P221, P252, P253.

Museum der Natur Historichen Gesellschaft ${ }^{89}$, Nuremberg, Alemania : P8, P16, P50, P291, P292, P293, P294.

Musée des Beaux Arts de Bordeaux ${ }^{90}$, Francia : P280. 
Musée d'Ethmographie ${ }^{91}$, Ginebra, Suiza : P74.

Museum für Völkerkunde ${ }^{92}$, Berlín, Alemania : P213 (IV ca 41307).

Museo Nacional de Costa Rica ${ }^{93}$, San José : P13 (23083), P17, P20 (23090), P21 (23927), P24, P36 (24634), P39 (23139), P56, P57, P69, P83, P84, P86 (23175), P92, P96, P103, P112, P114 (24067), P116 (15164), P134, P135 (9315), P149 (10557), P150 (15314), P153 (23906), P161 (9343), P162 (153139), P163 (15309), P164 (9332), P172 (23910), P176, P177, P186 (1510), P187 (27002), P191, P195, P198, P200, P205, P208, P223, P224, P248, P254 (15097), P262 (4200), P269 (1321), P278, P282, P296, P297 (15099), P298 (9305), P299 (21235), P323 (23381), P326 (22511).

National Museum of the American Indian ${ }^{94}$, Nueva York, E.E.U.U : P1, P5, P25, P26, P29, P30, P31, P32, P87, P106, P109, P148, P171, P189, P199, P203, P206, P226 (22321), P227 (22333), P228 (24256), P230, P231 (23756), P234, P236, P237, P238, P271, P272, P295.

Peabody Museum ${ }^{95}$, Universidad de Harvard, Cambridge, E.E.U.U : P85, P95, P124, P136, P137, P138, P139, P140, P141, P142, P151, P155, P159, P173, P175, P182, P190, P235, P275, P276, P284, P287, P288, P300, P301, P302, P303.

Reiss Museum ${ }^{96}$, Mannheim, Alemania : P52, P123, P244.

Saint Louis Art Museum ${ }^{97}$, Mississipi, E.E.U.U : P47. P77, P160, P215 (G-173).

United States National Museum ${ }^{98}$, Washington D.C. : P22, P23, P37, P94, P117, P118, P125, P130, P131 (528952), P132 (59969), P133 (60044), P144 (59970), P147 (28953), P233, $\mathrm{P} 277$.

\section{ANEXO II}

\section{REFERENCIAS DE LAS PIEZAS}

$\mathbf{P}$ (pieza cerámica) $+\mathrm{n}^{\circ}$ (atribuido para su estudio) + ref. museo. + ref. biblio.

P1, N.M.A.I, Lothrop 1926 vol. II ; P2, ?, Stone 1977 ; P3, ?, Squier 1853 ; P4, M.H, Baudez 1967 ; P5, N.M.A.I, Lothrop 1926 vol. II ;P6, M.H, Baudez 1967 ; P7, M.H, Baudez 1967 ; P8, M.N.H.G, Lehman-München 1913 ; P9, ?, Abel-Vidor et alii 1990 ; P10, ?, Ferrero 1987 ; P11, D.A.M, Lange ed. 1988 ; P12, I.N.S, Ferrero 1987 ; P13, M.N.C.R, " Tesoros del Arte... » 1971 ; P14, Col. Sackler, Katz ed. 1985 ; P15, ?, Stone 1977 ; P16, M.N.H.G, Lehman-München 1913 ; P17, M.N.H.G, Lehman-München 1913 ; P18, B.N.C.R, Ferrero 1987 ; P19, Col. J. de Roy, Stone 1977 ; P20, M.N.C.R, "Tesoros del Arte... » 1971 ; P21, M.N.C.R, Ferrero 1987 ; P22, U.S.N.M, Lothrop 1926 vol. II ; P23, U.S.N.M, Lothrop 1926 vol. II ; P24, M.N.C.R, Lothrop 1926 vol. II ; P25, N.M.A.I, Lothrop 1926 vol. II ; P26, N.M.A.I, Lothrop 1926 vol. II ; P27, ?, "Trésors du Nouveau Monde... " 1992 ; P28, Col. Sackler, Katz ed. 1985; P29, N.M.A.I, Lothrop 1926 vol. II ; P30, N.M.A.I, Lothrop 1926 vol. II ; P31, N.M.A.I, Lothrop 1926 vol. II ; P32, N.M.A.I, Lothrop 1926 vol. II ; P33, Col. Oduber, Stone 1977 ; P34, Col. Sackler; Katz ed. 1985 ; P35, I.N.S, Snarskis 1982 ; P36, M.N.C.R, com. pers. Borgnino / Lauthelin ; P37, U.S.N.M, Lothrop 1926 vol. II ; P38, Col. Calvo Fallas, Ferrero 1987 ; P39, M.N.C.R, Benson ed. 1981 ; P40, Col. Sackler, Katz ed. 1985 ; P41, Col. Sackler, Katz ed. 1985 ; P42, C.M, Hartman 1907 ; P43, C.M, Hartman 1907 ; P44, M.H, Baudez 1967 ; P45, M.H, Baudez 1967 ; P46, M.H, Baudez 1967 ; P47, S.L.A.M, Parsons 1980 ; P48, Col. Sackler, Katz ed. 1985 ; P49, I.N.S, Snarskis 1982 ; P50, M.N.H.G, Lehman-München 1913 ; P51, ?, Stone 1976 ; P52, R.M, « Federschlange... » 1982 ; P53, M.H, Baudez et alii 1992 ; P54, M.H, Baudez et alii 1992 ; P55, M.H, Baudez et alii 1992 ; P56, M.N.C.R, Lothrop 1926 vol. II ; P57, M.N.C.R, Lothrop 1926 vol. II ; P58, ?, Baudez 1967 ; P59, B.N.C.R, « L'art precolombien du Panama... »; P60, ?, Abel-Vidor et alii 1990 ; P61, ?, Stone 1977 ; P62, ?, Stone 1977; P63, ?, Stone 1977; P64, A.M.N.H, Lothrop 1926 vol. II ; P65, ?, Squier 1853 ; P66, ?, Squier 1853 ; P67, A.M.N.H, Lothrop 1926 vol. II ; P68, ?, « 126 Auktion... » ; P69, M.N.C.R, Lothrop 1926 vol. II ; P70, ?, Sweeney 1979 ; P71, M.A, Paz Cabello 1980 ; P72, M.A, Paz Cabello 1980 ; P73, ?, Stone 1977 ; 
P74, M.E.G, « Auto-portraits... » 1995 ; P75, Col. Sackler, Katz ed. 1985 ; P76, Col. Sackler, Katz ed. 1985; P77, Col. Sackler, Katz ed. 1985; P78, ?, «126 Auktion...»; P79, Col. Anderson, Lothrop 1926 vol. II ; P80, ?, Stone 1977 ; P81, ?, Lange 1993 ; P82, ?, Stone 1977 ; P83, M.N.C.R, Ferrero 1987 ; P84, M.N.C.R, Lines 1934 ; P85, P.M, Lothrop 1926 vol. II ; P86, M.N.C.R, Ferrero 1987 ; P87, N.M.A.I, Lothrop 1926 vol. II ; P88, A.M.N.H, Lothrop 1926 vol. II ; P89, Col. Balser, Ferrero 1987; P90, Col. Barbier-Mueller, "Arte Precolombino... » 1994 ; P91, Col. Herrera M., « Tesoros del Arte... » 1971 ; P92, M.N.C.R, « Tesoros del Arte... » 1971 ; P93, Col. Góngora U., « Tesoros del Arte... » 1971 ; P94, U.S.N.M, Lothrop 1926 vol. II ; P95, P.M, Lothrop 1926 vol. II ; P96, M.N.C.R, Lothrop 1926 vol. II ; P97, ?, Abel-Vidor et alii 1990 ; P98, Col. Anderson, Lothrop 1926 vol. II ; P99, I.N.S, Ferrero 1987 ; P100, ?, com. pers. Borgnino / Lauthelin ; P101, Col. Paéz H., com. pers. Borgnino / Lauthelin ; P102, ?, Stone 1977 ; P103, M.N.C.R, Stone 1977 ; P104, M.H, Baudez 1967 ; P105, M.H, Baudez 1967 ; P106, N.M.A.I, Lothrop 1926 vol. II ; P107, M.H, Baudez 1967 ; P108, M.H, Baudez 1967; P109, N.M.A.I, Lothrop 1926 vol. II ; P110, M.H, Baudez 1967 ; P111, M.H, Baudez 1967 ; P112, M.N.C.R, Quesada-López Calleja 1980; P113, Col. Acosta, Stone 1958; P114, M.N.C.R, Ferrero 1987 ; P115, I.N.S, Benson ed. 1981 ; P116, M.N.C.R, Benson ed. 1981 ; P117, U.S.N.M, Lothrop 1926 vol. II ; P118, U.S.N.M, Wilson 1896 ; P119, I.N.S, QuesadaLópez Calleja 1980 ; P120, Col. de Roy, Stone 1977 ; P121, Col. Paéz U. \& S., Benson ed. 1981 ; P122, Col. Paéz U. \& S., Benson ed. 1981 ; P123, R.M, « Federschlange... » 1982 ; P124, P.M, Lothrop 1926 vol. II ; P125, U.S.N.M, Lothrop 1926 vol. II ; P126, C.M, Hartman 1907 ; P127, C.M, Hartman 1907 ; P128, C.M, Hartman 1907 ; P129, C.M, Hartman 1907 ; P130, U.S.N.M, Lothrop 1926 vol. II ; P131, U.S.N.M, Wilson 1896; P132, U.S.N.M, Wilson 1896 ; P133, U.S.N.M, Wilson 1896 ; P134, M.N.C.R, Ferrero 1987 ; P135, M.N.C.R, Ferrero 1987 ; P136, P.M, Lothrop 1926 vol. II ; P137, P.M, Lothrop 1926 vol. II ; P138, P.M, Lothrop 1926 vol. II ; P139, P.M, Lothrop 1926 vol. II ; P140, P.M, Lothrop 1926 vol. II ; P141, P.M, Lothrop 1926 vol. II ; P142, P.M, Lothrop 1926 vol. II ; P143, C.M, Hartman 1907 ; P144, U.S.N.M, Baudez 1967 ; P145, M.H, Baudez 1967 ; P146, M.H, Baudez 1967 ; P147, U.S.N.M, Bransford 1881 ; P148, N.M.A.I, Lothrop 1926 vol. Il ; P149, M.N.C.R, Benson ed. 1981 ; P150, M.N.C.R, Benson ed. 1981 ; P151, P.M, Stone 1976 ; P152, ?, Abel-Vidor et alii 1990 ; P153, M.N.C.R, Benson ed. 1981 ; P154, Col. Paéz H., Benson ed. 1981 ; P155, P.M, Katz ed. 1985 ; P156, M.H, Baudez 1967 ; P157, M.H, Baudez 1967 ; P158, M.H, Baudez 1967 ; P159, P.M, Lothrop 1926 vol. II ; P160, S.L.A.M, Parsons 1980 ; P161, M.N.C.R, com. pers. Borgnino / Lauthelin ; P162, M.N.C.R, com. pers. Borgnino / Lauthelin; P163, M.N.C.R, com. pers. Borgnino/ Lauthelin ; P164, M.N.C.R, com. pers. Borgnino / Lauthelin ; P165, ?, Sweeney 1979 ; P166, ?, Guerrero M. 1986 ; P167, ?, Guerrero M. 1986 ; P168, ?, Guerrero M. 1986 ; P169, ?, Guerrero M. 1986 ; P170, Col. Dada, Baudez 1970 ; P171, N.M.A.I, Lothrop 1926 vol. II ; P172, M.N.C.R, com. pers. Borgnino / Lauthelin ; P173, P.M, Lothrop 1926 vol. II ; P174, ?, AbelVidor et alii 1990 ; P175, P.M, Lothrop 1926 vol. II ; P176, M.N.C.R, Lothrop 1926 vol. II ; P177, M.N.C.R, Lothrop 1926 vol. II ; P178, Col. Sackler, Katz ed. 1985; P179, Col. Sackler, Katz ed. 1985 ; P180, I.N.S, Ferrero 1987 ; P181, I.N.S, Ferrero 1987 ; P182, P.M, Stone 1977 ; P183, B.N.C.R, "L'Art précolombien du Panama... » 1978 ; P184, B. N.C.R, " L'Art précolombien du Panama... » 1978 ; P185, Col. Sackler, Katz ed. 1985 ; P186, M.N.C.R, Lothrop 1926 vol. II ; P187, M.N.C.R, com. pers. Borgnino / Lauthelin ; P188, I.N.S, Snarskis 1982 ; P189, N.M.A.I, Lothrop 1926 vol. II ; P190, P.M, Lothrop 1926 vol. II ; P191, M.N.C.R, Lothrop 1926 vol. II ; P192, Col. Sackler, Katz ed. 1985 ; P193, I.N.S, Benson ed. 1981 ; P194, Col. Sackler, Katz ed. 1985 ; P195, M.N.C.R, Lothrop 1926 vol. II ; P196, I.N.S, Stone 1977 ; P197, Col. J. de la Guardia, « Tesoros del arte... » 1971 ; P198, M.N.C.R, Lothrop 1926 vol. II ; P199, N.M.A.I, Lothrop 1926 vol. II ; P200, M.N.C.R, com. pers. Borgnino / Lauthelin ; P201, ?, Baudez 1970 ; P202, Col. Sackler, Katz ed. 1985 ; P203, Col. Sackler, Katz ed. 1985 ; P204, Col. Anderson, Lothrop 1926 vol. II ; P205, M.N.C.R, Lothrop 1926 vol. II ; P206, N.M.A.I, Lothrop 1926 vol. II ;P207, ?, Sweeney 1979 ; P208, M.N.C.R, Lothrop 1926 vol. II ; P209, Col. 
Barbier-Mueller; «Arte Precolombino... » 1994; P210, M.H, Baudez 1967; P211, ?, Stone 1976 ; P212, Col. Sackler, Katz ed. 1985 ; P213, M.F.V, Stone 1983 ; P214, ?, Abel-Vidor et alii 1990 ; P215, S.L.A.M, Parsons 1980 ; P216, ?, Sweeney 1979 ; P217, ?, Abel-Vidor et alii 1990 ; P218, C.M, Hartman 1907 ; P219, M.H, Baudez 1967 ; P220, Col. Sackler, Katz ed. 1985 ; P221, M.H, Baudez et alii 1992 ; P222, Col. Gillén, Day 1984 ; P223, M.N.C.R, Stone 1977 ; P224, M.N.C.R, Lothrop 1926 vol. II ; P225, ?, Lines 1936 ; P226, N.M.A.I, Bransford 1881 ; P227, N.M.A.I, Bransford 1881 ; P228, N.M.A.I, Bransford 1881 ; P229, B.M, Joyce 1916 ; P230, N.M.A.I, Wyckofl 1971 ;P231, N.M.A.I, Bransford 1881 ; P232, B.M, Joyce 1916 ; P233, U.S.N.M,Lothrop 1926 vol. II ; P234, N.M.A.I, Bransford 1881 ; P235, P.M, Lothrop 1926 vol. II ; P236, N.M.A.I, Wyckoff 1971 ; P237, N.M.A.I, Lothrop 1926 vol. II ; P238, N.M.A.I, Wyckoff 1971 ; P239, ?, Sweeney 1979 ; P240, ?, Lange 1976; P241, Col. Gillén, Day 1984; P242, Col. Gillén, Day 1984 ; P243, Col. Gillén, Day 1982 ; P244, R.M, "Federschlange... » 1982 ; P245, B.N.C.R, Ferrero 1987 ; P246, B.N.C.R, Ferrero 1987 ; P247, ?, Lange \& Stone 1984 ; P248, M.N.C.R, Stone 1977 ; P249, I.NS, Snarskis 1982 ; P250, ?, Abel-Vidor et alii ; P251, B.M, Joyce 1916 ; P252, M.H, Baudez et alii 1992 ;P253, M.H, Baudez et alii 1992 ; P254, M.N.C.R, Benson ed. 1981 ; P255, ?, Sweeney 1979 ; P256, ?, Sweeney 1979 ; P257, ?, Sweeney 1979 ; P258, ?, Sweeney 1979 ; P259, ?, Sweeney 1979 ; P260, ?, Sweeney 1979 ; P261, I.N.S, Snarskis 1982 ; P262, M.N.C.R, com. pers. Borgnino / Lauthelin ; P263, Col. Sackler, Katz ed. 1985 ; P264, Col. J. de Roy, Ferrero 1987 ; P265, Col. Sackler, Katz ed. 1985 ; P266, ?, Stone 1977 ; P267, I.N.S, Quesada-López Calleja 1980 ; P268, I.N.S, Quesada-López Calleja 1980 ; P269, M.N.C.R, com. pers. Borgnino / Lauthelin ; P270, M.N.C.R, com. pers. Borgnino / Lauthelin ; P271, N.M.A.I, Lothrop 1926 vol. II ; P272, N.M.A.I, Lothrop 1926 vol. II ; P273, C.M, Hartman 1907 ; P274, A.M.N.H, Lothrop 1926 vol. II ; P275, P.M, Lothrop 1926 vol. II ; P276, P.M, Lothrop 1926 vol. II ; P277, U.S.N.M, Lothrop 1926 vol. II ; P278, M.N.C.R, Quesada-López Calleja 1980 ; P279, I.N.S, Snarskis 1982 ; P280, M.B.A.B, Desrayaud 1996; P281, Col. Sackler, Katz ed. 1985 ; P282, M.N.C.R, Quesada-López Calleja 1980 ; P283, Col. Acosta, Stone 1958 ; P284, P.M, Lothrop 1926 vol. II ; P285, Col. Gamboa P., " Tesoros del Arte... " 1971 ; P286, Col. Anderson, Lothrop 1926 vol. II ; P287, P.M, Lothrop 1926 vol. II ; P288, P.M, Lothrop 1926 vol. II ; P289, C.M, Hartman 1907 ; P290, I.N.S, « Centro America... " 1992 ; P291, M.N.H.G, Lehman-München 1913 ; P292, M.N.H.G, Lehman-München 1913 ; P293, M.N.H.G, Lehman-München 1913 ; P294, M.N.H.G, Lehman-München 1913 ; P295, N.M.A.I, Lothrop 1926 vol. II ; P296, M.N.C.R, Stone 1977 ; P297, M.N.C.R, Lothrop 1926 vol. II ; P298, M.N.C.R, com. pers. Borgnino / Lauthelin ; P299, M.N.C.R, com. pers. Borgnino / Lauthelin ; P300, P.M, Stone 1972 ; P301, P.M, Stone 1972 ; P302, P. M, Stone 1972; P303, P.M, Stone 1972 ; P304, Col. M. de Ruenes, com. pers. Borgnino / Lauthelin ; P305, Col. M. de Ruenes, com. pers. Borgnino / Lauthelin ; P306, Col. Oduber, com. pers. Borgnino / Lauthelin ; P307, Col. Oduber, com. pers. Borgnino / Lauthelin ; P308, Col. Paéz H., com. pers. Borgnino / Lauthelin ; P309, Col. Paéz H., com. pers. Borgnino / Lauthelin ; P310, B.N.C.R, com. pers. Borgnino / Lauthelin ; P311, I.N.S, com. pers. Borgnino / Lauthelin ; P312, Col. Oduber, com. pers. Borgnino / Lauthelin ; P313, Col. Robelo A., com. pers. Borgnino / Lauthelin ; P314, Col. Paéz H., com. pers. Borgnino / Lauthelin ; P315, Col. Oduber, com. pers. Borgnino / Lauthelin ; P316 / 317, Col. Oduber, com, pers. Borgnino / Lauthelin ; P318, Col. Oduber, com. pers. Borgnino / Lauthelin ; P319, Col. Dada L., com. pers. Borgnino/ Lauthelin ; P320, Col. Paéz H., com. pers. Borgnino / Lauthelin ; P321, Col. Dada L., com. pers. Borgnino / Lauthelin ; P322, Col. Dada L., com. pers. Borgnino / Lauthelin ; P323, M.N.C.R, com. pers. Borgnino / Lauthelin ; P324, Col. Oduber, com. pers. Borgnino / Lauthelin ; P325, Col. Dada L., com. pers. Borgnino/Lauthelin ; P326, M.N.C.R, com. pers. Borgnino / Lauthelin. 


\section{AVISO ACERCA DE LAS ILUSTRACIONES}

Las figuras y dibujos presentados a continuación tienen como objetivo dar un complemento visual al texto.

Por razones documentales (dibujos esquemáticos a partir de fotos), enl la mayoria de los casos no fue posible respetar las normas técnicas ortométricas de dibujo.

En muchos casos no se pudieron conseguir las dimensiones exactas de las piezas; eso se traduce por las abreviaciones siguientes :

" e.d» (escala desconocida),

«e.h » (escala hipotética)

$y$ « e.a » (escala aproximativa).

Las escalas se dan en centímetros. 


\begin{tabular}{|c|c|c|c|c|c|c|c|c|c|c|c|}
\hline vegiones & Chontsles & Ometepe & Rivas & $\begin{array}{l}\text { Salinss } \\
\mathrm{s}^{2} \text { Elens }\end{array}$ & $\begin{array}{l}\text { Bashia de } \\
\text { Culebra }\end{array}$ & $\begin{array}{l}\text { Mratapalo } \\
\text { Nosarj }\end{array}$ & $\begin{array}{l}\text { Valle del } \\
\text { Tempisque }\end{array}$ & $\begin{array}{l}\text { Cordillesa } \\
\text { occidental } \\
\text { Guanusaste }\end{array}$ & دños & $\begin{array}{l}\text { Periodizacion } \\
\text { serśmics }\end{array}$ & $\begin{array}{l}\text { Periodizatión } \\
\text { "Cuajiniquil' }\end{array}$ \\
\hline \multirow{2}{*}{$\left.\begin{array}{l}1500 \\
1400 \\
1300 \\
1200 \\
1100\end{array}\right]$} & CUAS'A & $\frac{\text { Sta } A N A}{\text { S. LAZARO }}$ & $\begin{array}{c}\text { MLA } \\
\text { GRACHA }\end{array}$ & \multirow{2}{*}{$\begin{array}{c}\text { A } \\
\text { wCRUZ } \\
\text { li }\end{array}$} & RUIZ & \multirow{2}{*}{$\begin{array}{c}A \\
\text { BL:BE. } \\
\text { DENC) } \\
B\end{array}$} & \multirow{2}{*}{$\begin{array}{l}\text { DA:Bt:- } \\
\text { DFEO }\end{array}$} & FII ANA & \multirow{2}{*}{$\begin{array}{l}1500 \\
1400 \\
1300\end{array}$} & $\begin{array}{l}\text { POLICRONO } \\
\text { RECIENTE }\end{array}$ & ONETLPE \\
\hline & MONOIA & PALONA & $\begin{array}{l}\text { LAS } \\
\text { LANAS }\end{array}$ & & $\begin{array}{l}\text { IGIA- } \\
\text { NITA }\end{array}$ & & & \multirow{3}{*}{ siltsicio } & & \multirow[b]{2}{*}{$\begin{array}{c}\text { POLLCROMIO } \\
\text { MEDIO }\end{array}$} & \multirow[b]{2}{*}{ SAPOA } \\
\hline $\begin{array}{l}1000- \\
900 \\
800\end{array}$ & FOTRERO & GATO & AFOMIOA & $\begin{array}{c}\text { Dor } \\
\text { clevios }\end{array}$ & BANAMA & \multirow[t]{2}{*}{$\begin{array}{l}\text { TANAS } \\
\text { NNIXI }\end{array}$} & \multirow[t]{2}{*}{$\begin{array}{c}\text { PAIOO } \\
\text { HLANCO }\end{array}$} & & $\begin{array}{l}1200 \\
1100 \\
1000 \\
900 \\
800\end{array}$ & & \\
\hline $\begin{array}{l}700 \\
600 \\
500\end{array}$ & \multirow[t]{2}{*}{ CUISALA } & S. ROQUE & P.NECROS & $S^{\text {ta }}$ ELENA & CUIEBW & & & & $\left.\begin{array}{l}700 \\
600 \\
500\end{array}\right]$ & $\begin{array}{l}\text { POLICROMO } \\
\text { ANTIGUO }\end{array}$ & \multirow{2}{*}{ BAGACES } \\
\hline $\begin{array}{l}400 \\
300\end{array}$ & & \multirow[b]{2}{*}{ MANAMEI } & S. ROQUF: & $\begin{array}{c}\text { MURCIE- } \\
\text { IAKOO }\end{array}$ & Ar. Uvi & MENAS & CIRURLASI & \multirow{2}{*}{$\frac{\text { ARFNAI. }}{1}$} & \multirow{4}{*}{$\begin{array}{c}300 \\
200 \\
100 \\
0 \\
100 \\
200 \\
300 \\
400 \\
500 \\
\end{array}$} & \multirow{4}{*}{$\begin{array}{l}\text { BICRONO } \\
\text { EN ZONAS }\end{array}$} & \\
\hline $\begin{array}{c}200 \\
100 \\
0\end{array}$ & \multirow[t]{2}{*}{$\begin{array}{c}\text { MAYALES } \\
1\end{array}$} & & S. JORGE & \multirow{3}{*}{ CHOMEO } & \multirow{3}{*}{ ORSO } & \multirow{3}{*}{$\begin{array}{l}\text { MONYE- } \\
\text { FRFSCO }\end{array}$} & \multirow{3}{*}{$\operatorname{CATAIINA}$} & & & & \\
\hline $\begin{array}{l}100 \\
200\end{array}$ & & SINICAPA & \multirow[b]{2}{*}{ AVILES } & & & & & & & & ISQUE \\
\hline $\begin{array}{l}300 \\
400 \\
300 \\
\end{array}$ & $\begin{array}{c}\text { MAXAES } \\
2\end{array}$ & ANGELES & & & & & & $\begin{array}{c}\text { ARENAL } \\
2\end{array}$ & & & \\
\hline & $\begin{array}{l}\text { Cosin } \\
1959\end{array}$ & $\begin{array}{l}\text { Healy } \\
1980\end{array}$ & $\begin{array}{l}\text { Healy } \\
1930\end{array}$ & $\begin{array}{l}\text { Basdez } \\
\text { \& Coe } \\
\text { 19s2 }\end{array}$ & $\begin{array}{l}\text { Longe } \\
\text { ct aliti } \\
1935\end{array}$ & $\begin{array}{l}\text { Baudez } \\
\& \text { Coe } \\
1962\end{array}$ & $\begin{array}{l}\text { Baudez } \\
1957\end{array}$ & $\begin{array}{c}\text { Hoopes } \\
1934\end{array}$ & & Vázquezel & Ifii 1931 \\
\hline
\end{tabular}

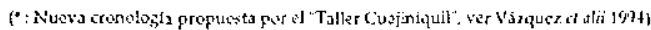

FIG. 1. - Periodización regional de la zona de Gran Nicoya

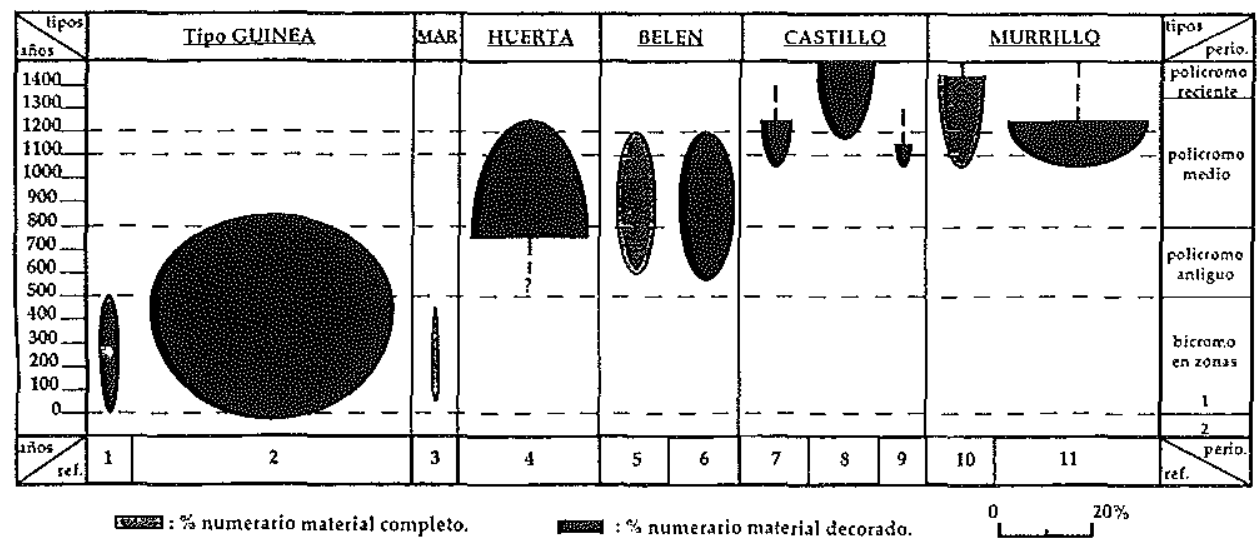

1 : Baudez 1967, sitios del Valle del Tempisque; 2 : Seguin Sweeney 1979, sitios de Matapalo (upits $7 \& 8$ \&) Chahuite Escondido, 6 fechas C $14 ; 3$ : Baudez 1987, sitios del Valle del Tempisque; 4 : Segín Swerney 1979, sitio de Huerta del Aguacate (" pits 1 \& 2 "), 5 fechas C" ; 5 : Baudez 1967, sitios del Valle del Tempisque ; 6 : Serun Sweeney 1979, sitios de Hlueria del A quacate, Matapalo y Chahuite Escondido, 16 fechas CH 7 : Segín Sweeney 1979 , sitios de Huerta del Aouacate y Chahuite Escondido, 4 fechas $C^{14} ; 8$ : Healy 1980, Isla de Ometepe; $9:$ Healy 1980, sitios del Istmo de Rivas; $10:$ Baudez 1967 , sitios del Valle del Tempisque; 11 : Según Sweeney 1979 , sitio de Chahuite Escondido ( pit l "), 4 fechis C"

FIG. 2. - Secuencias cerámicas de los tipos monocromos grabados / incisos (aproximaciones según datos bibliográficos) 


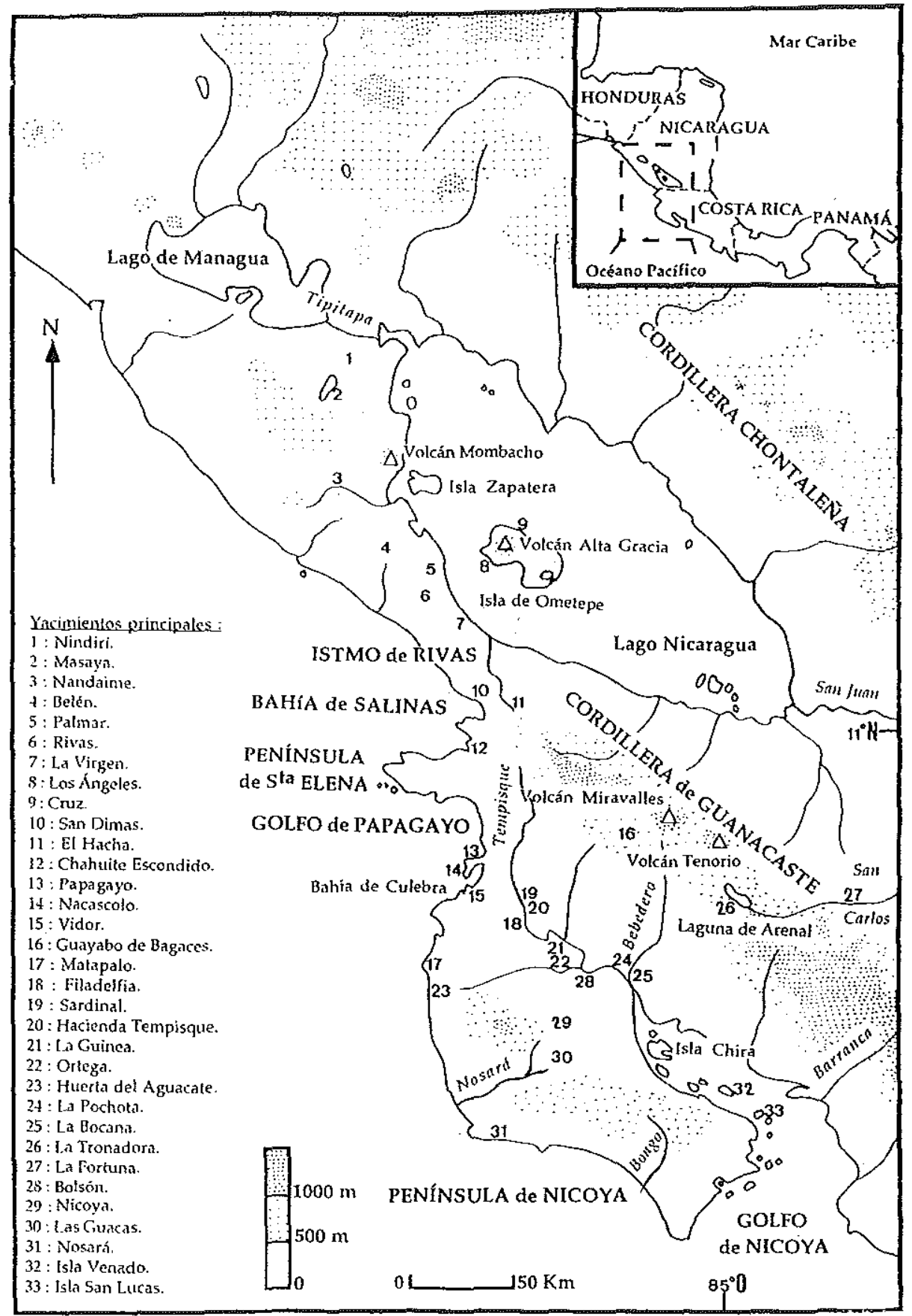

FIG. 3. - Mapa orográfico y de los principales sitios de la zona de Gran Nicoya 


\begin{tabular}{|c|c|c|c|c|c|c|c|c|c|}
\hline \multirow{2}{*}{\multicolumn{2}{|c|}{ formas }} & \multicolumn{4}{|c|}{ Instrumentos de música } & \multicolumn{3}{|c|}{ Figurillas } & \multirow{3}{*}{$\begin{array}{l}\text { for } \\
\text { tot } \\
0\end{array}$} \\
\hline & & \multirow[t]{2}{*}{$\begin{array}{l}\text { Oca- } \\
\text { rinas }\end{array}$} & \multirow[t]{2}{*}{ Pitos } & \multirow[t]{2}{*}{ Maracas } & \multirow[t]{2}{*}{$\begin{array}{l}\text { "Tam- } \\
\text { bores" }\end{array}$} & \multirow[t]{2}{*}{ de pie } & \multirow[t]{2}{*}{ sentadas } & \multirow[t]{2}{*}{ otras } & \\
\hline \multirow{25}{*}{$\begin{array}{l}\mathrm{Z} \\
\mathrm{O} \\
\mathrm{O} \\
\mathrm{M} \\
\mathrm{O} \\
\mathrm{R} \\
\mathrm{F} \\
\mathrm{O} \\
\mathrm{S}\end{array}$} & reptil ind. & & & & & & & & \\
\hline & serpiente & & & & & & & & 0 \\
\hline & iguana & & & & & & & & \\
\hline & cocodrilo & $\mathrm{M}$ & & & & & & & \\
\hline & ciervo & & & & & & & & 0 \\
\hline & pelicano & & & & & & & & \\
\hline & rapaz diuma & & & & & & & & \\
\hline & buitre & & & & & & & & 0 \\
\hline & reptil alado & & & & & & & & \\
\hline & tortuga & & & & & & & & \\
\hline & cánido & & & & & & & & 0 \\
\hline & murciélago & $G M$ & & & & & & & \\
\hline & pecarí & GG MMM & & & & & & & \\
\hline & "felino "bicéf." & $M$ & & & & & & & 1 \\
\hline & batracio & & & & & & & & \\
\hline & tatú & MMMMM & & & & & & & \\
\hline & ave "bicéf." & MMMM & & & & & & & 4 \\
\hline & zoo. indet. & $8 \mathrm{M}$ & GM & & & & & & 10 \\
\hline & felino & MM & & & & & & & \\
\hline & estrígida & & & & & & & & 0 \\
\hline & murcié. + rept. & & & & & & & & \\
\hline & ave ind. & $10 \mathrm{M}$ & & & & & & & 10 \\
\hline & mono & & & & & & & & 0 \\
\hline & cocod:"bicéf." & & & & & & & & \\
\hline & ind. "bicéf." & & & & & & & & \\
\hline \multirow{9}{*}{$\begin{array}{l}\mathrm{A} \\
\mathrm{n} \\
\mathrm{t} \\
\mathrm{r} \\
\mathrm{o} \\
\mathrm{p} \\
\mathrm{o} \\
.\end{array}$} & sianieses & & & & & G & & & 1 \\
\hline & hombre & & & & & & & & \\
\hline & hermafró. & & & & & 6 & & & \\
\hline & homb. \& muj. & & & & & & & G. & 1 \\
\hline & "descanso" & & & & & & & & \\
\hline & mujer & $\mathrm{GM}$ & & & & $18 \mathrm{G} \mathrm{Mfu}$ & $8 \mathrm{GH}$ & G & 31 \\
\hline & indet. & $8 \mathrm{M}$ & $M$ & & & $\mathrm{MH} \mathrm{Mlu}$ & & & 12 \\
\hline & cefalómorfo & & & & & & & & \\
\hline & cabez + braz. & & & & & & & & 0 \\
\hline \multirow{9}{*}{$\begin{array}{ll}\mathrm{A} \\
\mathrm{n} \\
\mathrm{I} & \mathrm{z} \\
\mathrm{r} & \mathrm{o} \\
\mathrm{o} & \mathrm{o} \\
\mathrm{p} & \\
\mathrm{o} \\
.\end{array}$} & "homb.sapo", & & & & & & & & 0 \\
\hline & person. alado & & & & & GGMB & GM & & 6 \\
\hline & "homb. reptil" & M. & & & & MMM & & & \\
\hline & "homb. ave" & & & & & $M$ & & & \\
\hline & person indet. & & & & & SGM & G & & 4 \\
\hline & "homb. felino" & & & & & & & & \\
\hline & "homb.coco." & & & & & & & & \\
\hline & $\begin{array}{c}\text { decorado no- } \\
\text { figurativo }\end{array}$ & $M$ & G C & G & & & & & \\
\hline & coro. tot. & 52 & 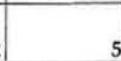 & 1 . & 0 & 35 & 12 & 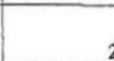 & 108 \\
\hline \multicolumn{5}{|c|}{$\begin{array}{c}\text { CONJUNTOS } \\
\text { ICONO-MORFOLOGICOS. }\end{array}$} & \multicolumn{4}{|c|}{$\begin{array}{l}\text { :Trad. istmeña (ant. s. IXd. C). } \\
\text { G: Pieza de Tipo Guinca. } \\
\text { M:Marbella. B: Belón. H: Huerfa. } \\
\text { C:Castillo. Mlu:Murrillo. }\end{array}$} & $\begin{array}{c}+ \\
3 \\
\text { ind } \\
\text {. }\end{array}$ \\
\hline
\end{tabular}

FIG. 4. - Cuadro cruzado icono-morfológico : instrumentos de música y figurillas 


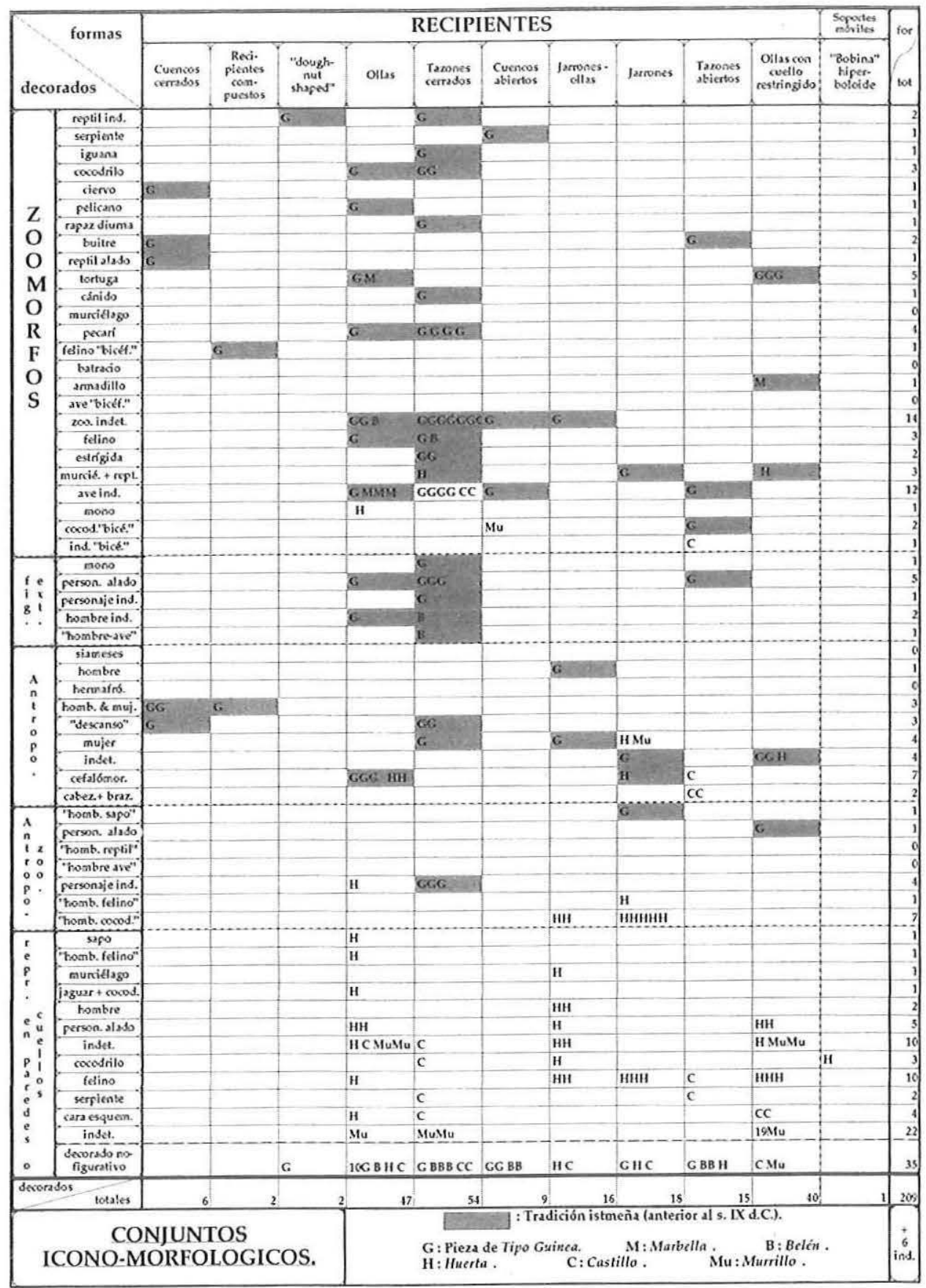

FIG. 5. - Cuadro cruzado icono-morfológico : recipientes y soportes móviles 

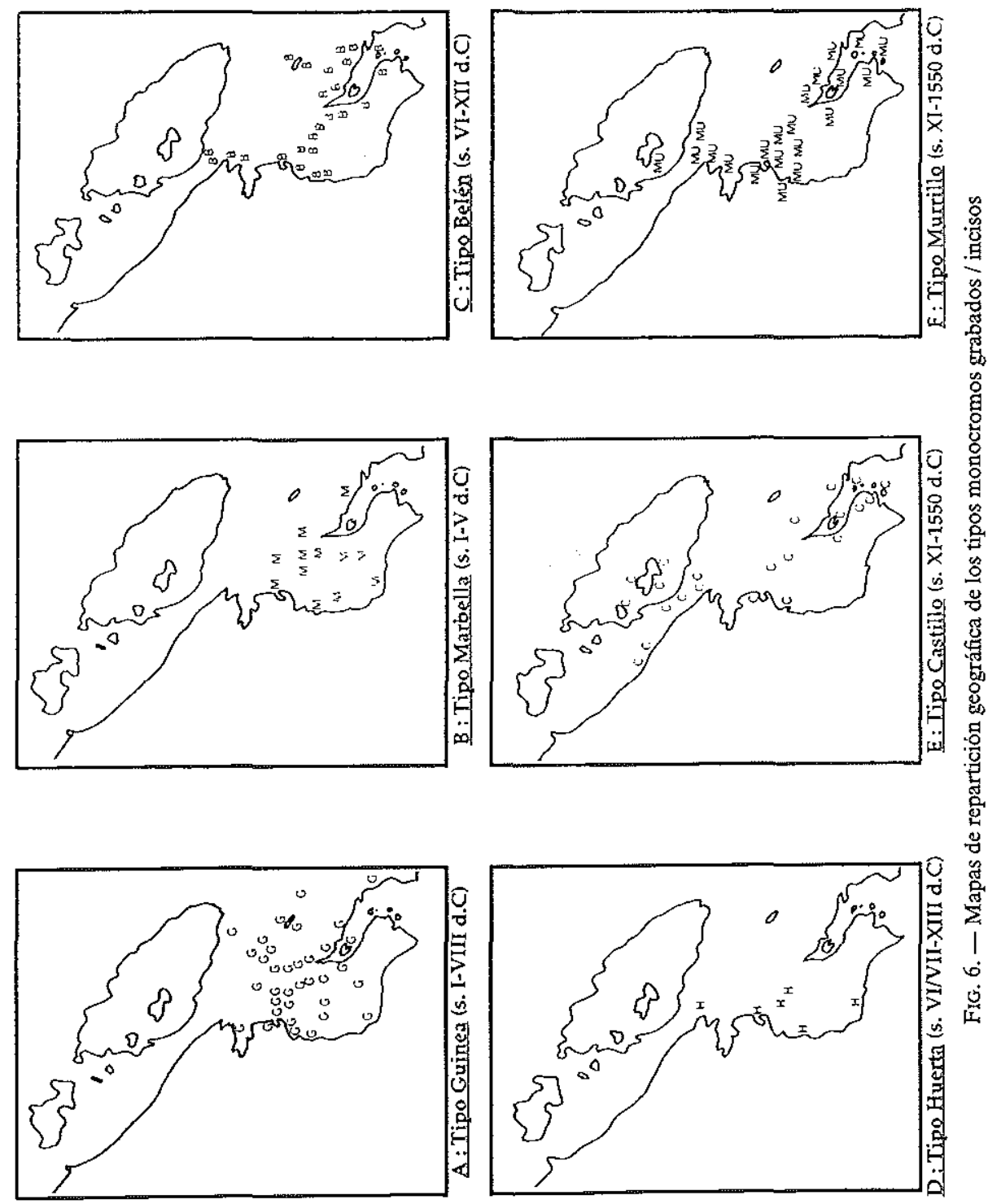


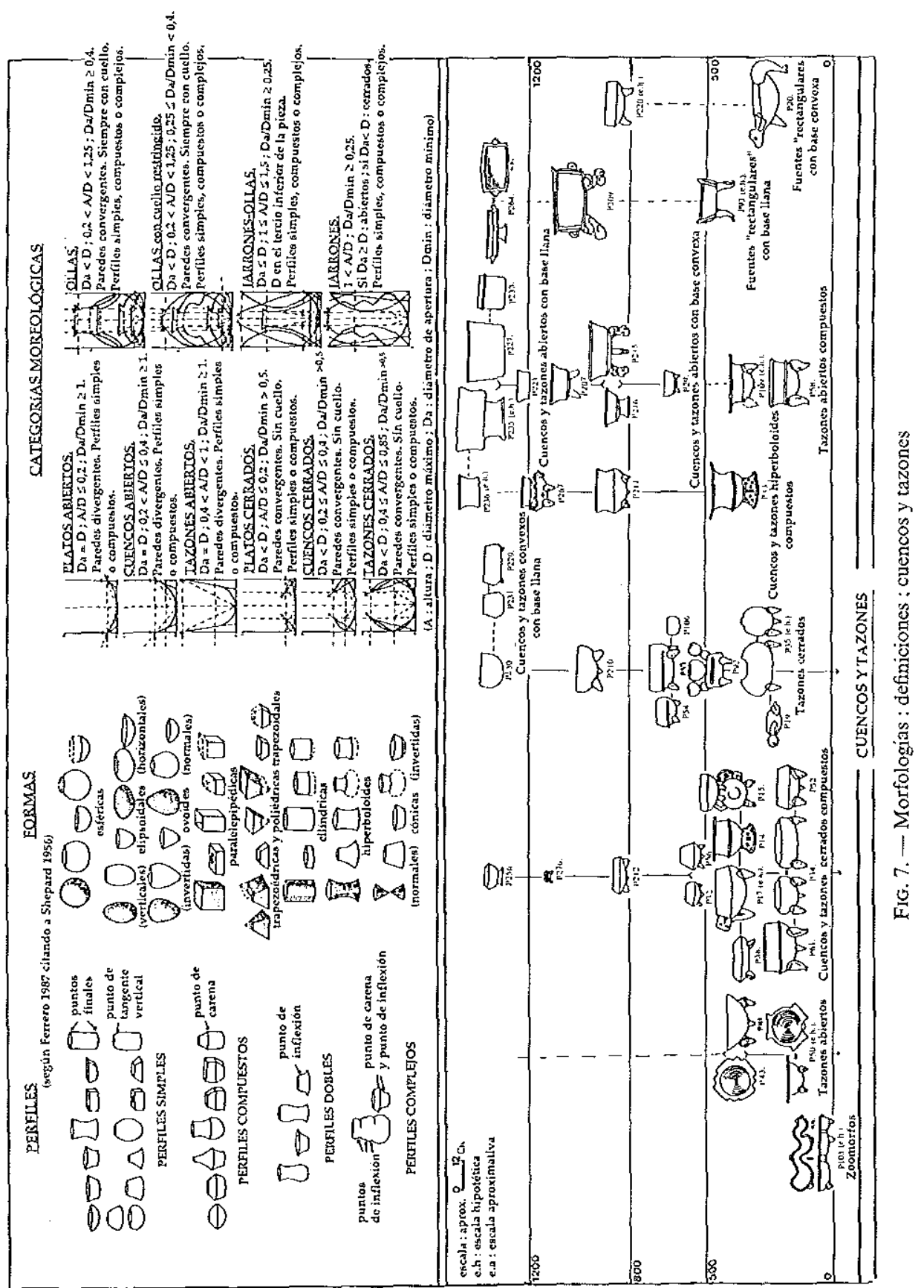




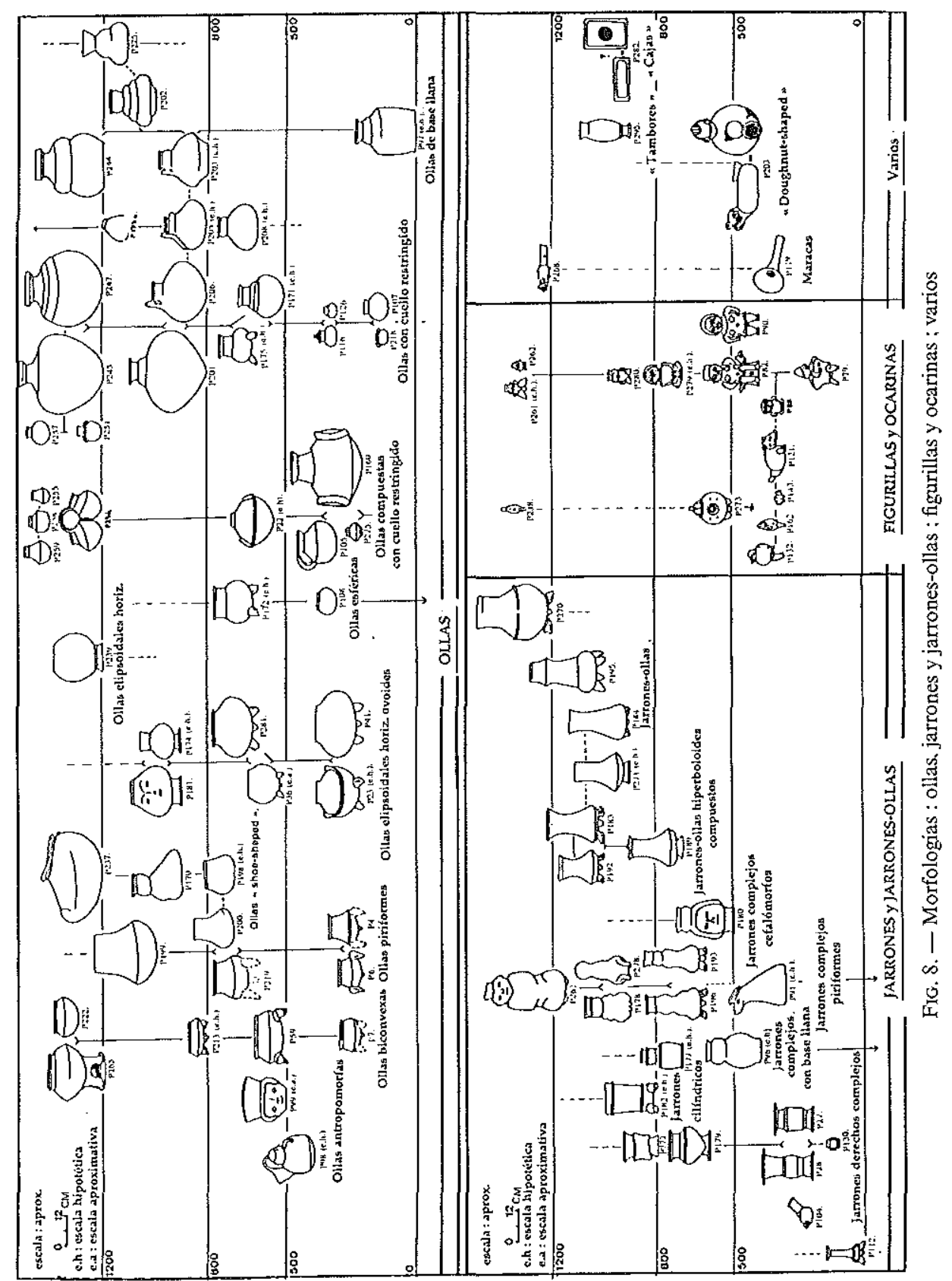



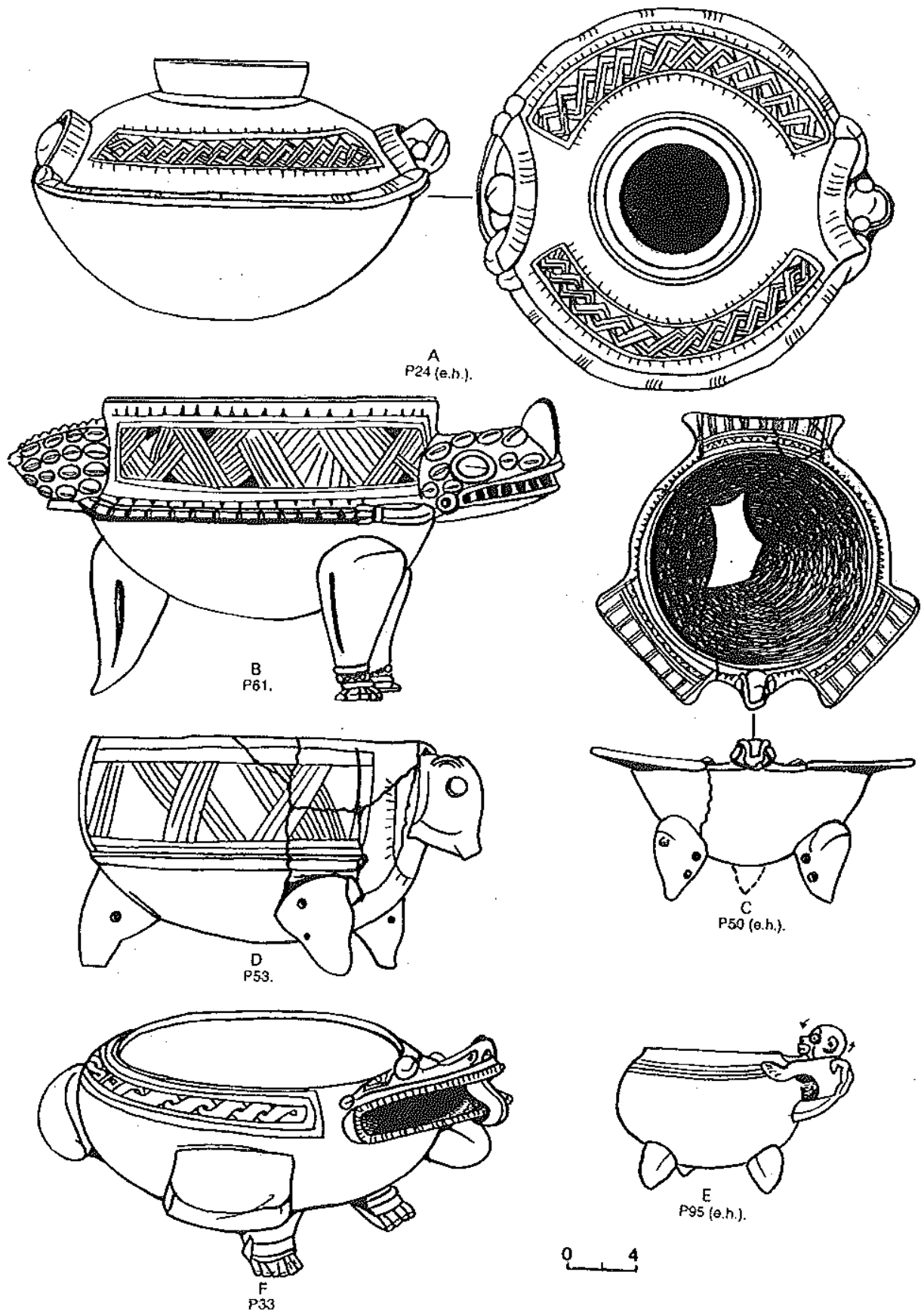

$\underset{1 \quad 4}{0.4}$

A : Museo Nacional de Costa Rica ; B : ?, ver Stone 1977; C : Museum der Natur Historichen Gesellschaft ; D : Mituse de l'Homme ; E : Peabody Museum.

FIG. 9. - Tipo Guinea grabado / inciso 

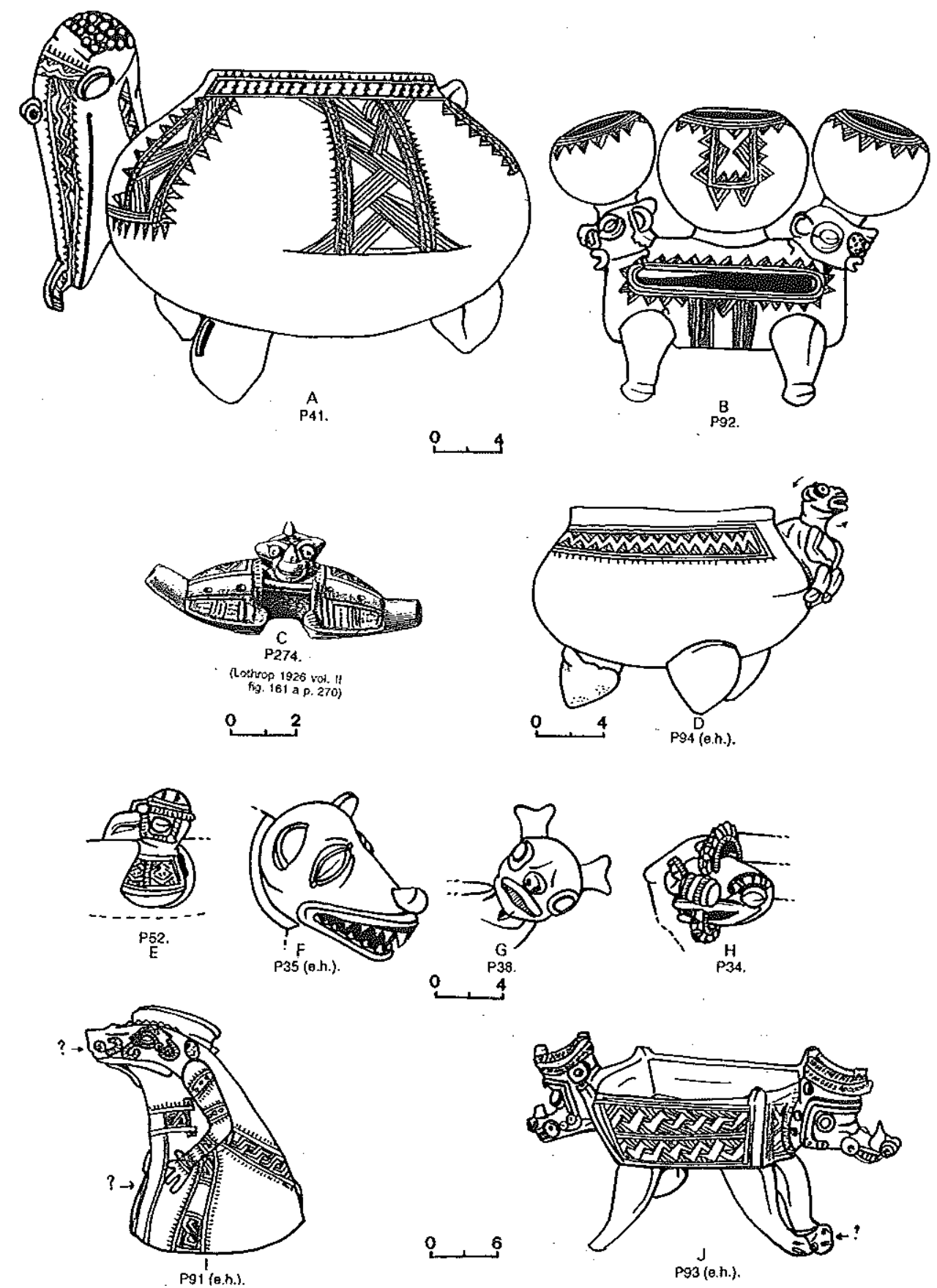

A : Col. Sackler ; B : Museo Nacional de Costa Rica ; C : American Museum of Natural History ; D : United States National Museum; B : Reiss Museum ; F : Instituto Nacional de Seguros ; G : Col. Calvo Fallas ; H : Col. Sackler ; I : Col. Herrera M. ; J : Col. Góngora U.

FIG. 10. - Tipo Guinea grabado / inciso 

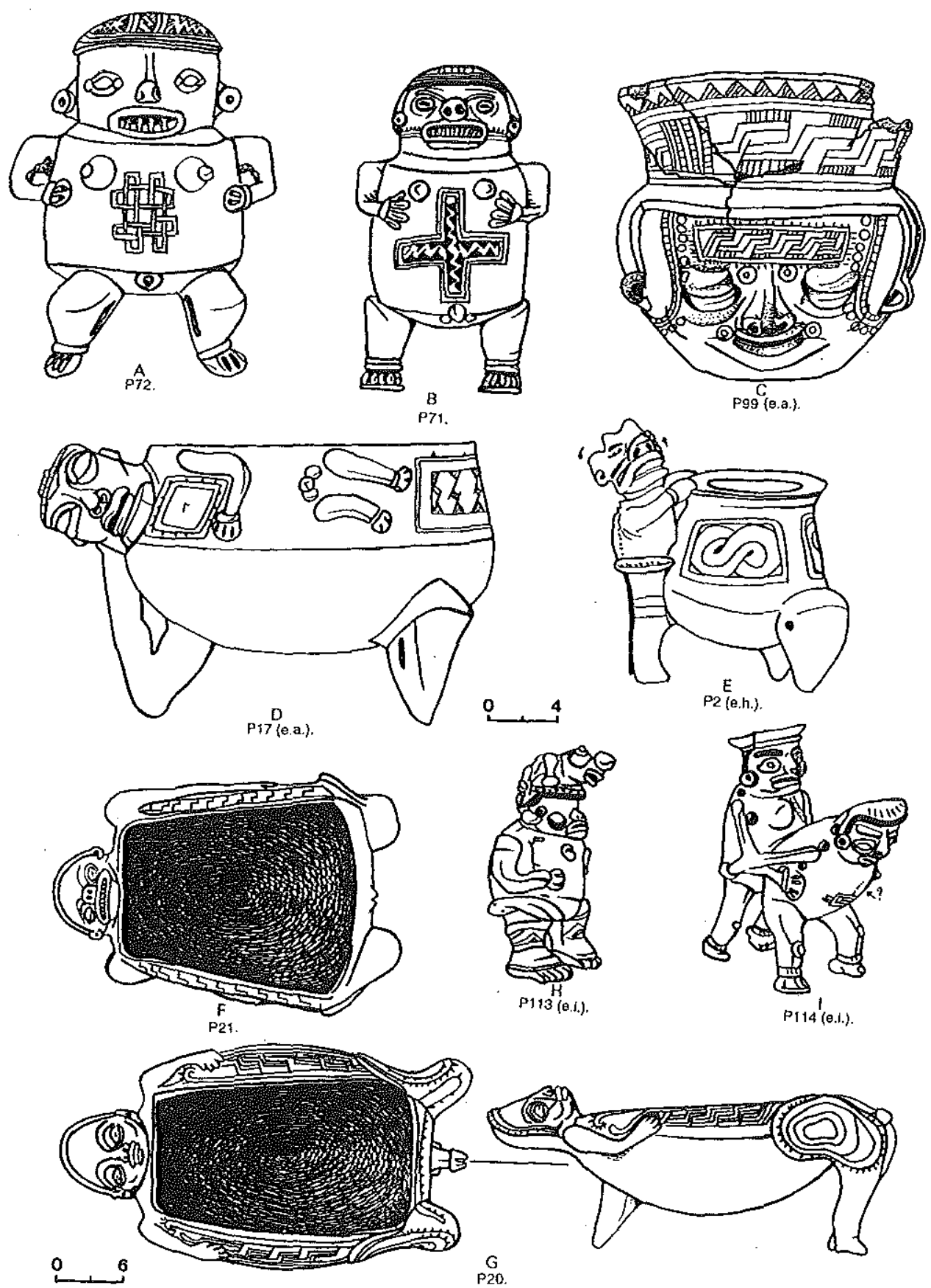

A : Museo de América ; B : Museo de América ; C : Instituto Nacional de Seguros ; D : Museum der Natur Historichen Geseltschaft; E : ?, ver Stone 1977; F/G : Museo Nacional de Costa Rica; H : Col. Acosta ; I : Museo Nacional de Costa Rica.

FIg. 11. - Tipo Guinea grabado / inciso 

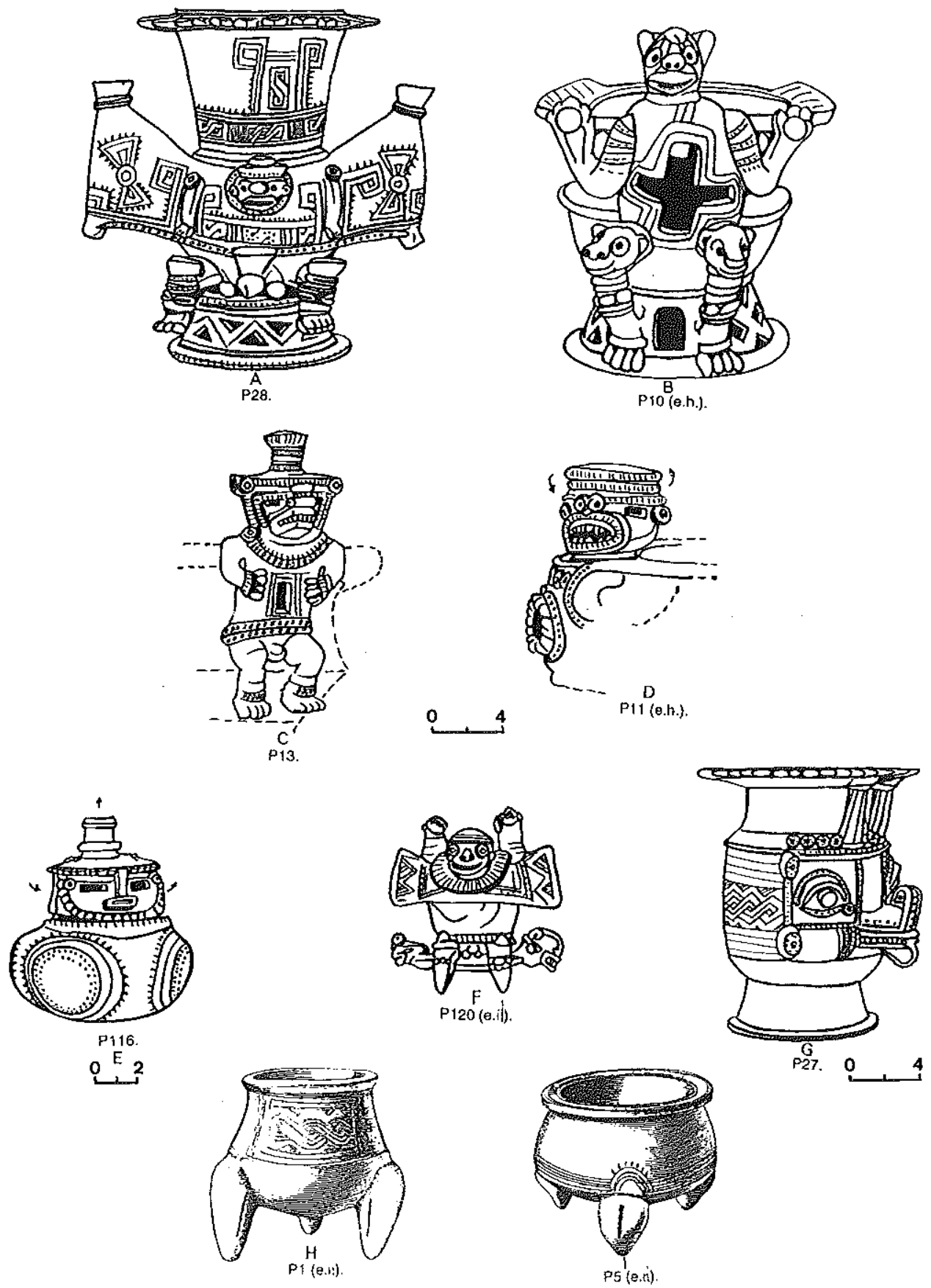

A : Col. Sackler ; B : ?, ver Ferrero 1987 ; C : Museo Nacional de Costa Rica ;

D : Denver Art Museum; E : Museo Nacional de Costa Rica ; F : Col. J. de Roy;

G : ?, ver "Trésors du Nowveau Monde.." 1992; H/I : National Museum of the American Indian.

FIG. 12. - Tipo Guinea grabado / inciso 

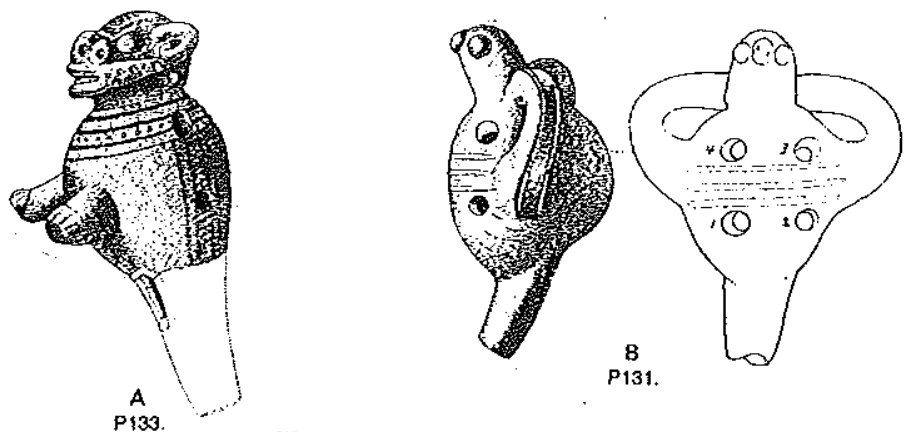

PI33.

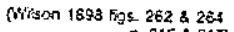
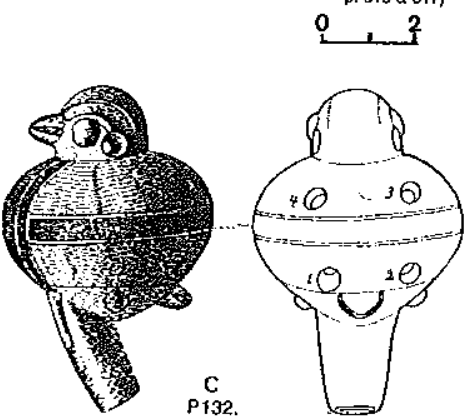

Mison $1839 \mathrm{fg} .263$ p. 616)
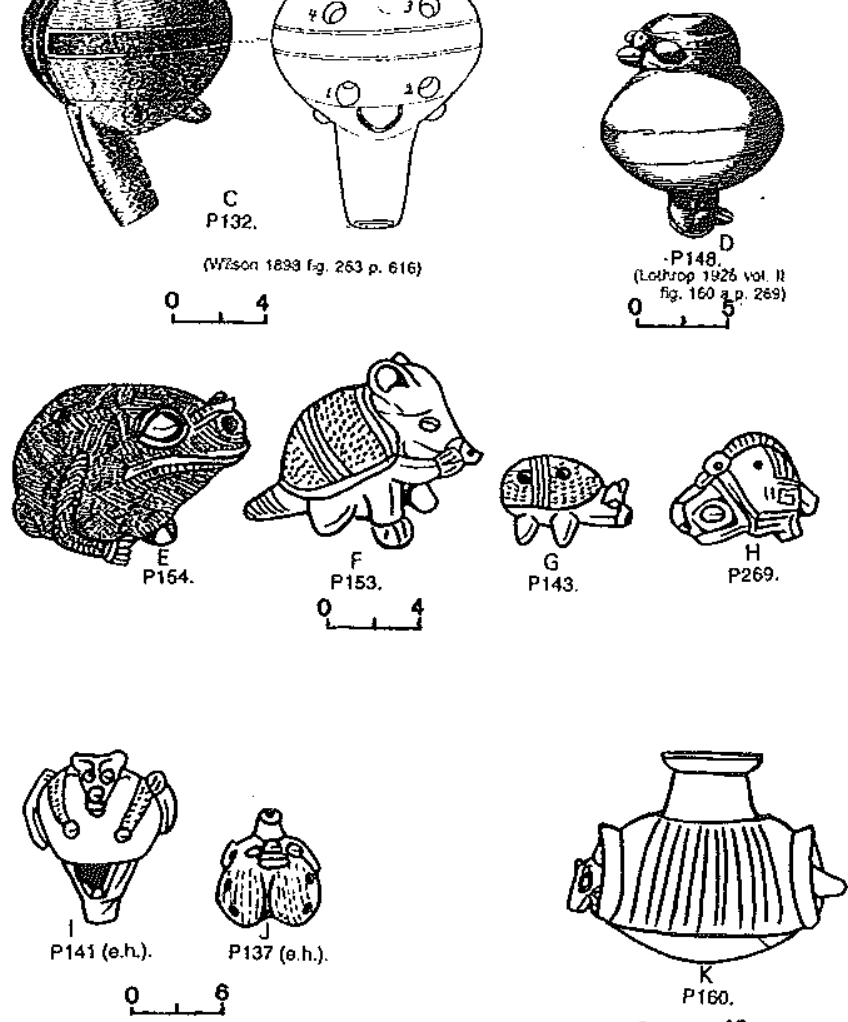

P

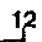

A.C: United States National Mfuseun! ; : National Museurn of the American Indian ;

E : Col. Paéz H. ; F : Museo Nacional de Costa Rica ; G : Camegie Museum;

H : Museo Nacional de Costa Rica ; $1 / J$ : Peabody Mfuseum ; K : Saint Louis Ant Museum

FIG. 13. - Tipo Marbella inciso / puntuado 

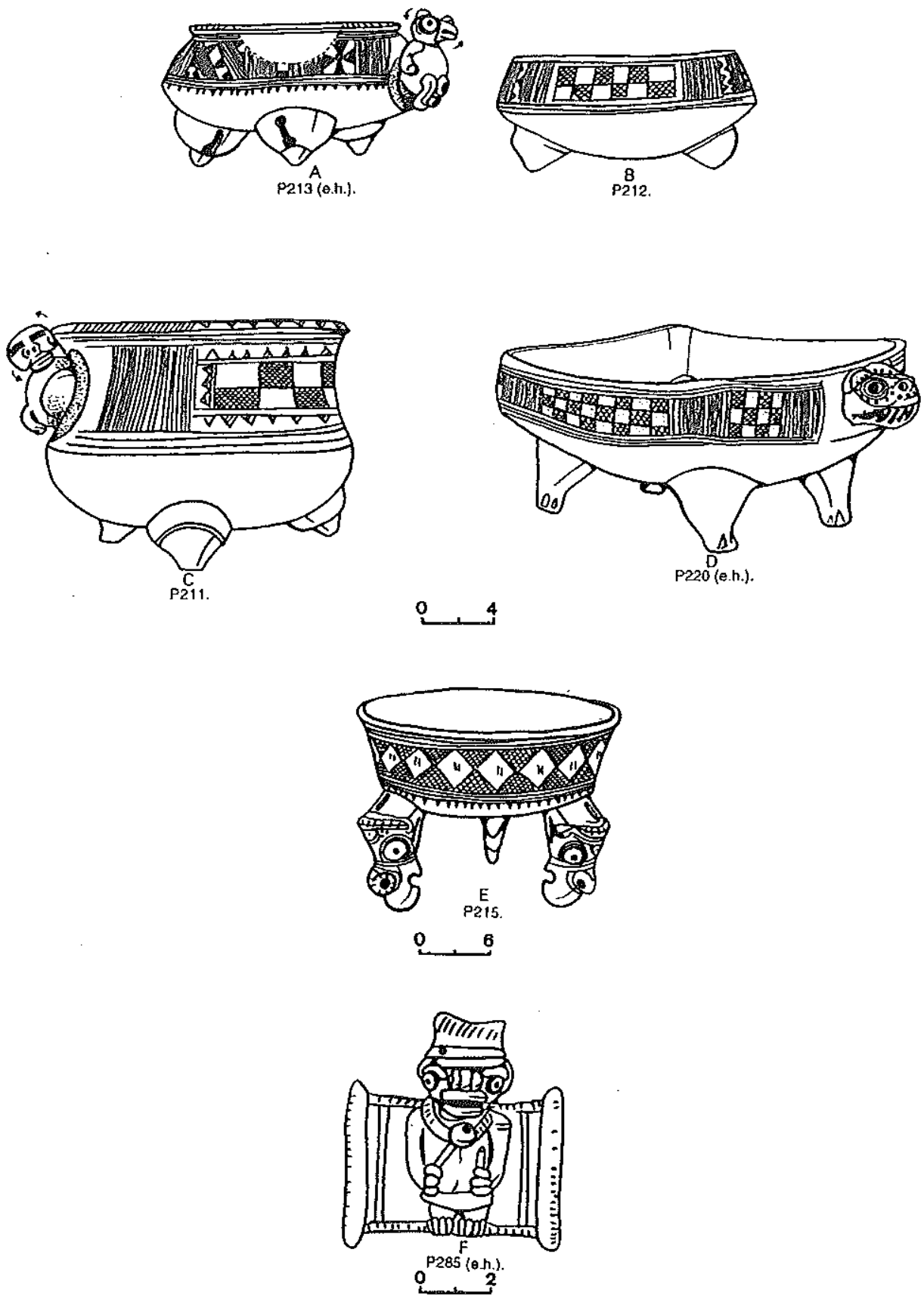

A : Museum für Volkerkunde ; B : Col. Sackler ; C : ?, ver Stone 1976; D : Col. Sackler ; E : Saint Louis Art Museum ; F : Col. Gamboa P.

Fig. 14. - Tipo Belén grabado / inciso 

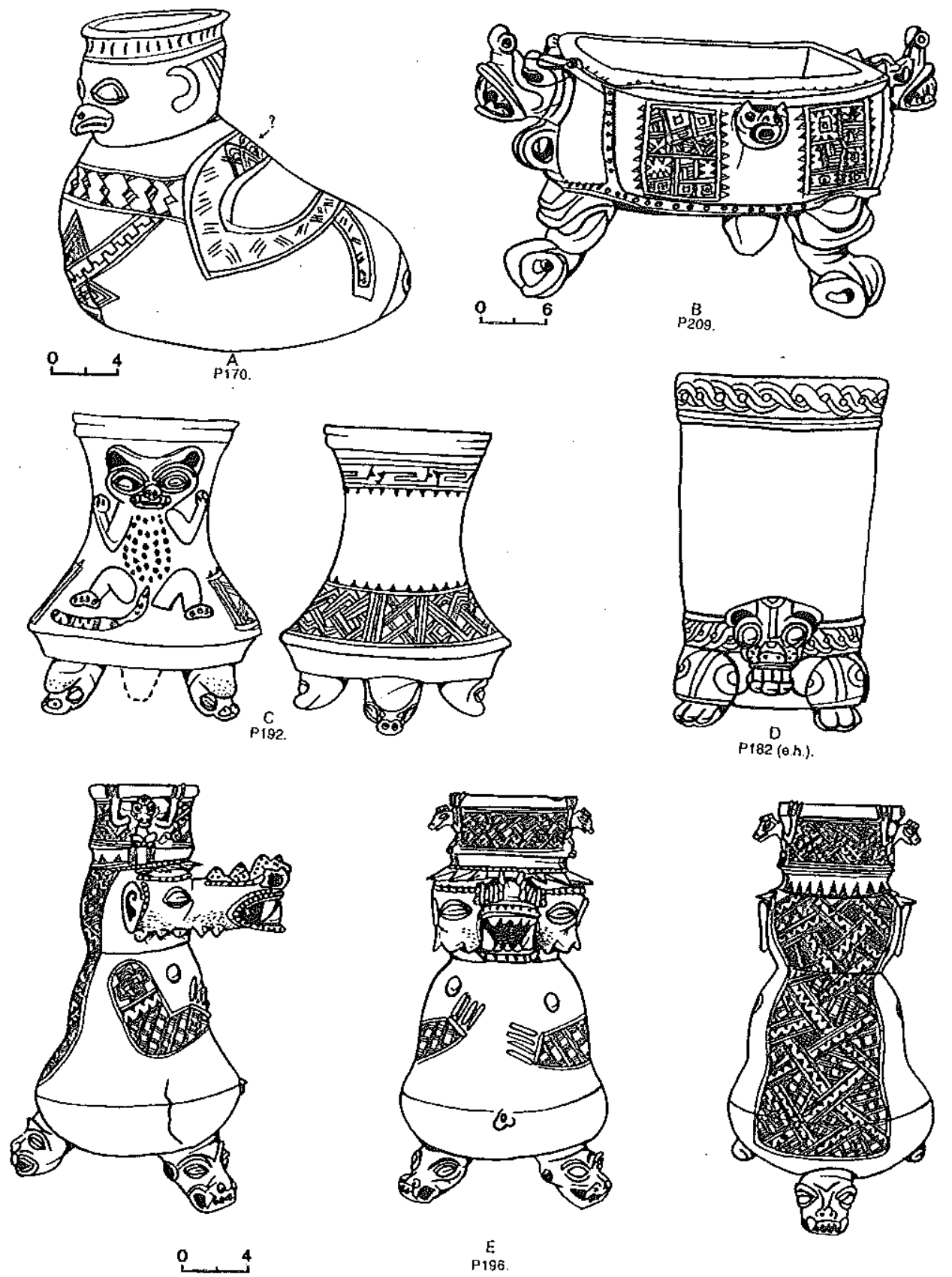

A : Col. Dada L. ; B : Col. Barbier-Mfueller ; C : Col. Szckler ; D : Peabody Museun ; $\mathrm{E}$ : Instituto Nacional de Seguros.

FIG. 15. - Tipo Huerta grabado / inciso 

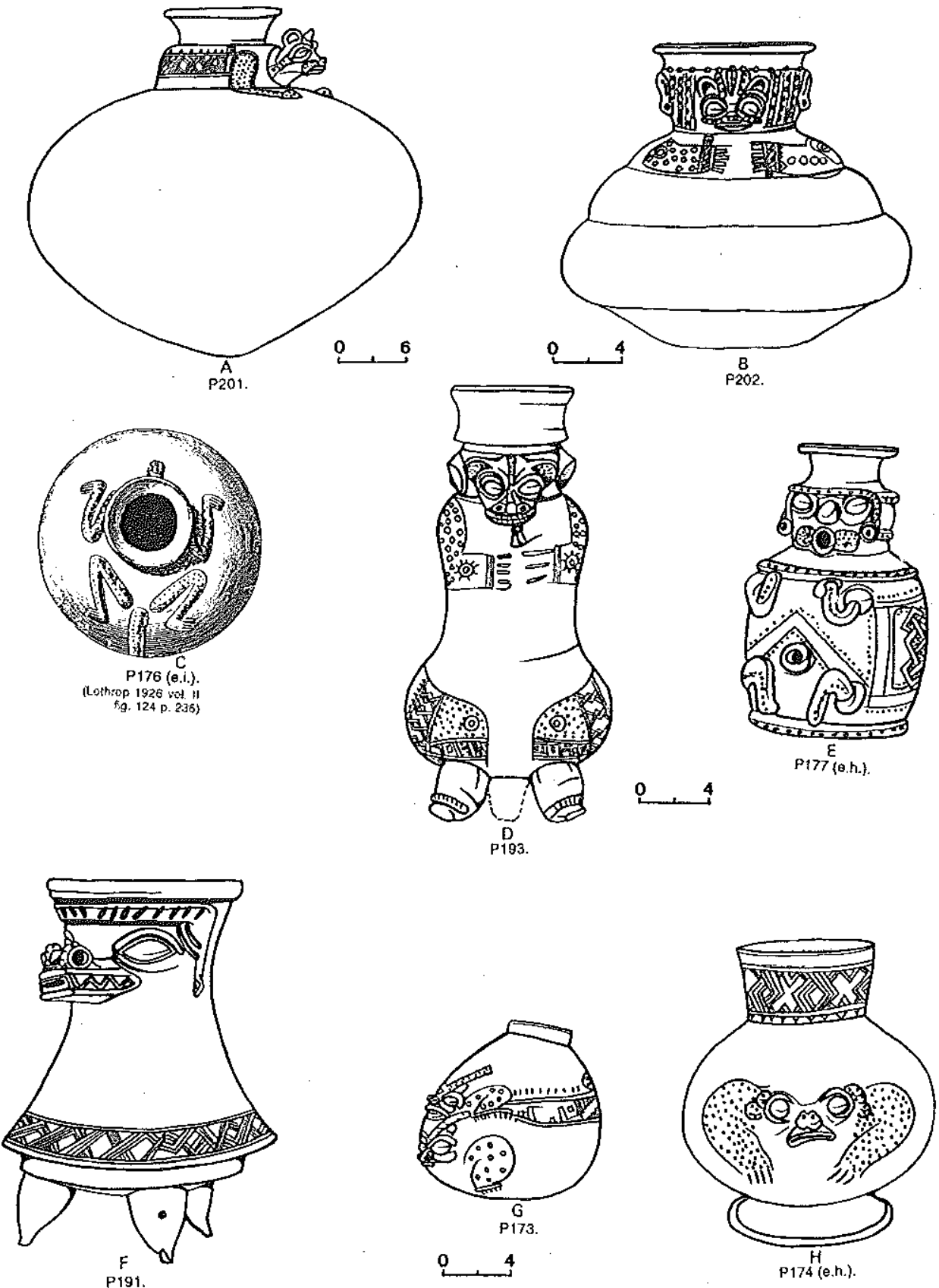

A : ? ver Baudez $1970 ;$ B : Col Sackler ; C : Museo Nacional de Costa Rica;

D : Instituto Nacional de Seguros; ENF : Museo Nacional de Costa Rica ; $G$ : Peabody Museum ; $H$ :? ver Abel-Vidor th alii 1990 .

Fig. 16. - Tipo Huerta grabado / inciso 

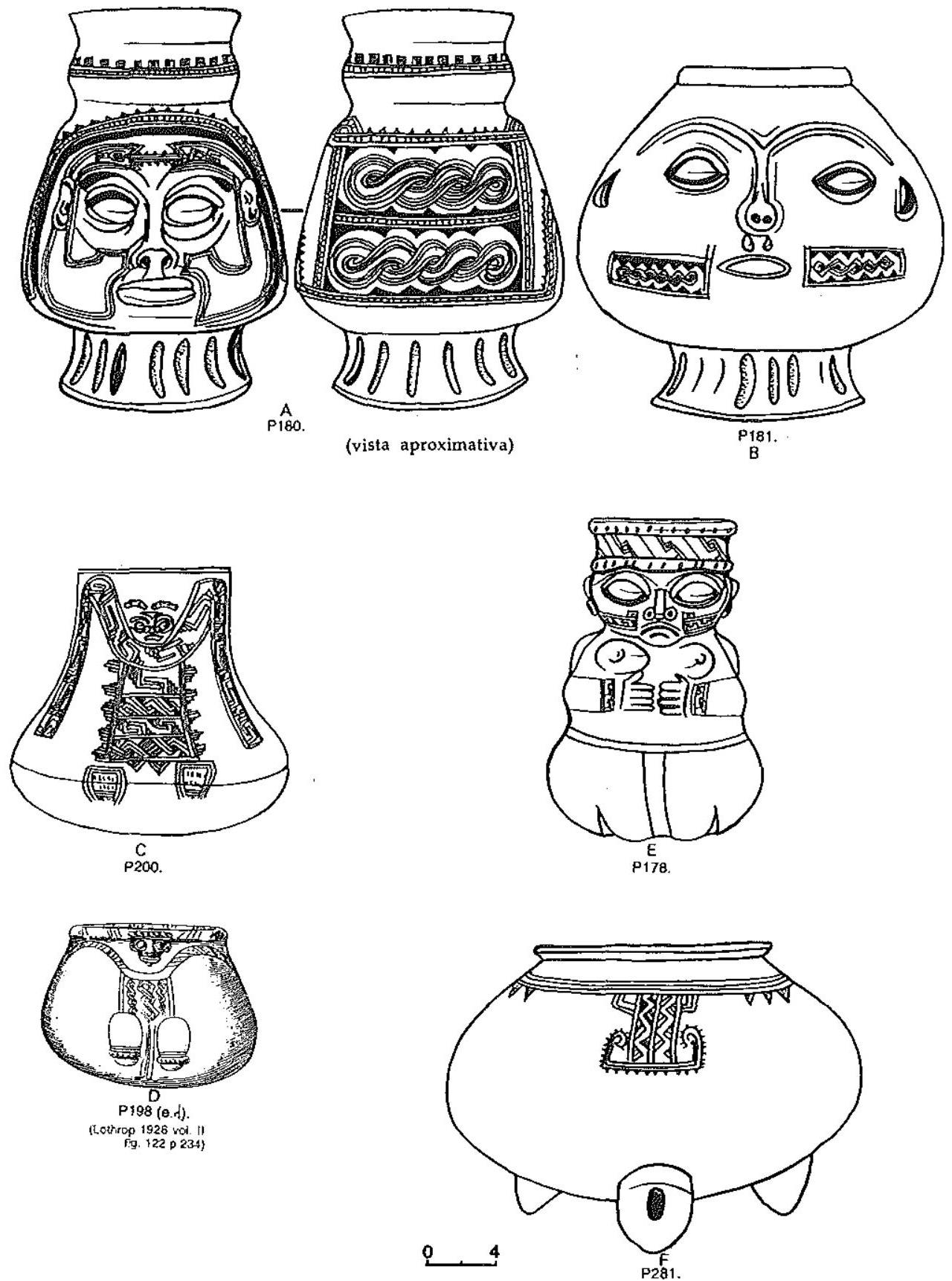

A/B : Instituto Nacional de Seguros ; C/D : Museo Nacional de Costa Rica ; E/F : Col. Sackler.

FIG. 17. - Tipo Huerta grabado / inciso 

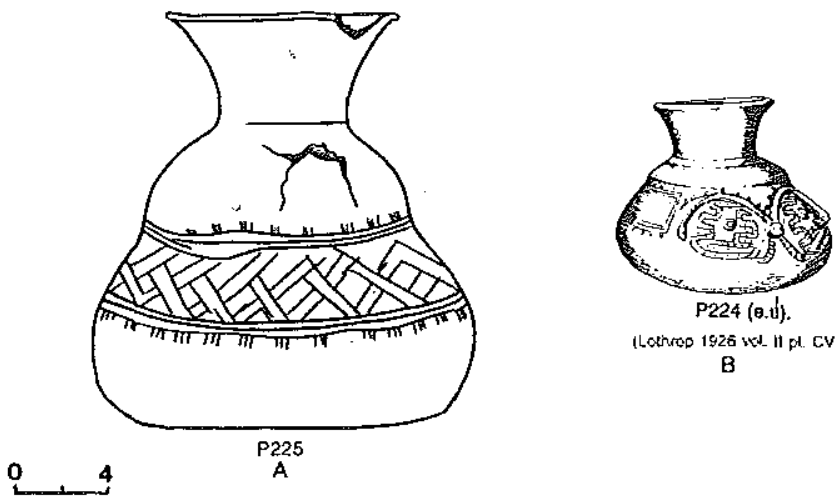

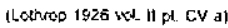

B
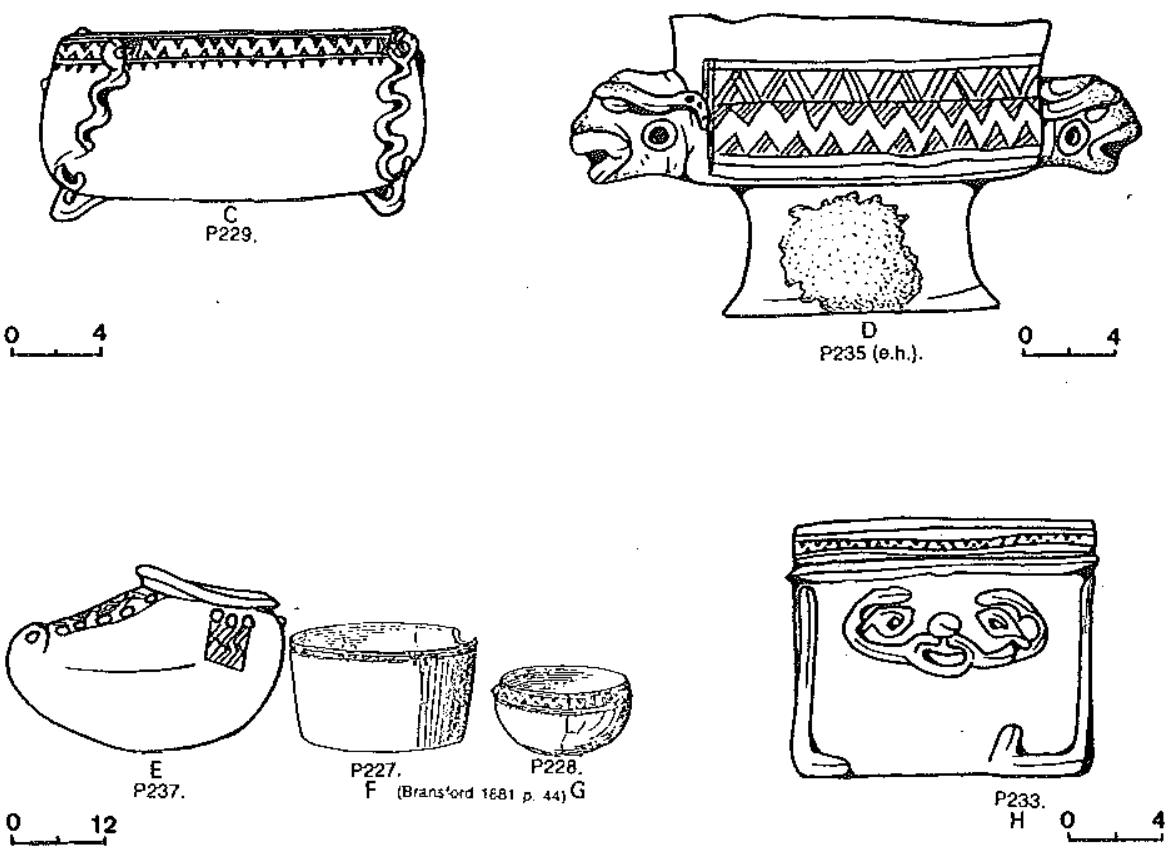

$0 \quad 12$

A : ?, ver Lines 1936 ; B : Museo Nacional de Costa Rica ; C : British Museum ; D : Peabody Museum; E.G : National Museum of the American Indian; H : United States National Mfuseum.

FIG. 18. - Tipo Castillo esgrafiado 

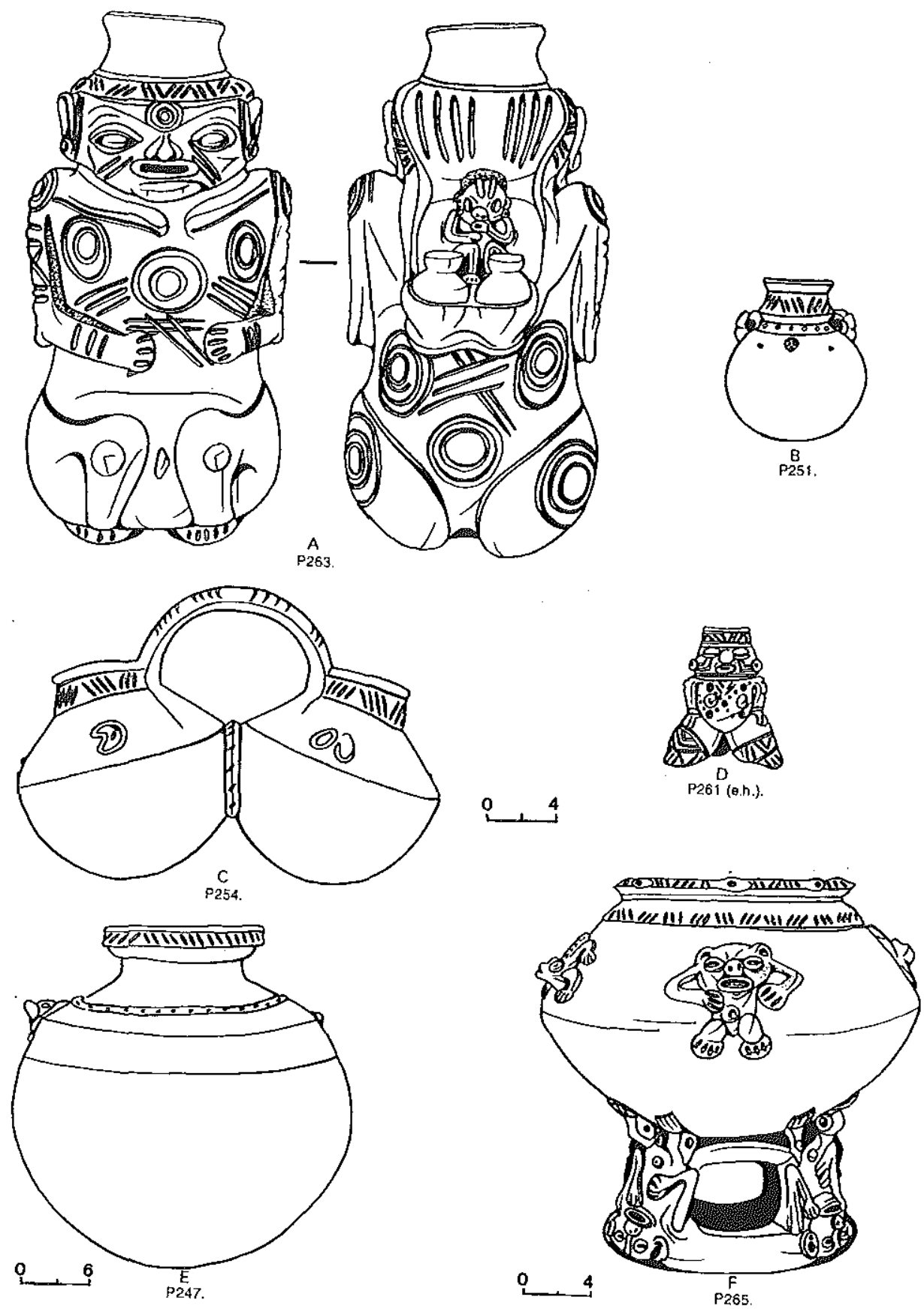

A : Col. Sackler; B : British Museum ; C : Museo Nacional de Costa Rica ;

D : Instituto Nacional de Segutos ; E : ?, ver Lange \& Stone 1984 ; F : Col. Sackler.

FIG. 19. - Tipo Murrillo inciso 


\section{NOTAS}

\section{Agradecimientos}

Quiero agradecerles por su ayuda tanto para la obtención de datos como por sus consejos a Claude F. Baudez, Nathalie Borgnino y Valérie Lauthelin. Les agradezco también a Julio Bendezú Sarmiento y a Ernesto Montenegro por sus correcciones, y al Service Régional d'Archéologie de Martinique por su ayuda logística.

1. Para una visión general sobre el desarrollo histórico del concepto de Gran Nicoya véanse Lange y Stone 1984, Ferrero 1987, Graham Miller ed. 1993, Constenla Umaña 1994, y Lange 1994.

2. Veánse Lange 1993, Fonseca Zamora 1994, y Vásquez L. et alii 1994.

3. Estudio realizado para la obtención del "Diplôme d'Études Approfondies" de quinto año en la Universidad de Paris I «Panthéon-Sorbonne », presentado en junio del 1998.

4. Lo que había llevado Claude F. Baudez y Michael D. Coe (1962) a crear un periodo de « decoración linear » entre 300 y 500 d.C. Ese período fue luego integrado al Bicromo en Zonas después del Congreso de San José en el 1986 (Lange 1994).

5. Figurilla pegada en la pared exterior de la vasija. A menudo hueca con cabeza móvil.

6. Pieza $n^{\circ} 276$, Peabody Museum, en Lothrop 1926, vol. II, pp. 278, Figura 172-c y n 299, Museo Nacional de Costa Rica $n^{\circ} 21235$, com. pers. N. Borgnino / V. Lauthelin.

7. Pieza n²51, British Museum, en Joyce 1916, lám. IV-2.

8. Véase Cooke 1993.

9. Para referencias zoológicas véanse Grzimek 1974 \& 1990 y Janzen 1983.

10. Véase pieza $n^{\circ} 84$, figurando a siameses, Col. ?, Lines 1934, Figura 110, pp. 75.

11. Tipo Guinea, véanse Figura $10 \mathrm{I}$, colgantes de piedra de Las Huacas en Hartman 1907 lám. XLI, tipo Rosales en Katz ed. 1985, pp. 21, Figura 14.

12. Tipo Murrillo, véase Figura 19 F. Colgantes de guanin en Lange et alii 1986, pp. 33.

13. Rosales, Bocana, Galo, Carrillo y Potosi en Lothrop 1926, vol. II, lám. CXXIV, Ferrero 1987, pp. 64, Abel Vidor et alii 1990 , pp. 137.

14. También ejemplar de Galo en Lothrop 1926, vol. II, lám. CXXI-a y de tipos más tardíos, pp. 262 y en Quesada López-Calleja 1980.

15. Véase «Trésors... »1992, pp. 259.

16. Rosales en Katz ed. 1985, « metate » de piedra en Holmes 1908, pp. 129, con una posible excepción más tardía del tipo Papagajo en Cemtro America 1992, pp. 205.

17. Veánse tipos Huerta, Galo en Ferrero 1987, pp. 84, Figura 148, Papagayo en Centro America 1992, pp. $342, \mathbf{n}^{\circ} 168$ y Tesoros... 1971, pp. 84.

18. Véase colgante de guanín del Panamá en Trésors... 1992, pp. 276, Figura 252 : felino devorando a un hombre.

19. "Metate » de piedra en Ferrero 1987, pp. 45, 109 y 127, Rosales y Mora en Centro America 1992, pp. 173 y 238.

20. Bocama en Lothrop 1926, vol. II, lám. CXXXIV, Rosales en Ferrero 1987, pp. 67, Chávez blanco sobre rojo en Abel Vidor 1990, pp. 190 B-C.

21. Col. privada, Costa Rica, Ferrero 1987, Figura II-32 y Lange 1976, Figura E, pp. 62. Para la región del Diquís, véase figurilla de venado comiendo una panoja de maís, guanín, en Benson ed. 1981, pp. 223, $\mathrm{n}^{\circ} 261$.

22. Mazo de piedra en Benson 1981, pp. 186, $n^{\circ} 48$, colgantes de piedra verde y Bocana en Hartman 1907 , lám. X-a y Ferrero 1987, pp. 74, 308 y 398.

23. Buhos, lechuzas,... Figura 15 A ; véanse mazos de piedra en Hartman 1907, lám. XXVII, Ferrero 1987 lám. V-B y Trésors... 1992, pp. 258, Papagajo en Ferrero 1987, pp. 91, Figura 164.

24. Halcones, arpias,... pieza $n^{\circ} 47$ en Parsons 1980 Figura 337. Véase ocarina policroma figurando un ave rapaz devorando un pez en Centro America 1992, pp. 350 n $^{\circ} 207$.

25. Veánse mazos de piedra y posiblemente un « metate » en Ferrero 1987 lám. Var, Figura VIII-4: 123 y Figura VIII-5, pp. 279, Birmania en Snarskis 1982, pp. 63 y vasija de piedra de Nicaragua en Trésors... 1992, pp. 266. 
26. Col. Oduber, Costa Rica, en Stone 1977, pp. 156, Figura 210.

27. Vallejo en Lothrop 1926, vol. I, lám. LXXXV y Benson ed. 1981, pp. 198, nº 111-112.

28. Tipo Huerta, Col. privada Ligia Dada n 130, Costa Rica, comunicación personal de N. Borgnino y V. Lauthelin.

29. Pieza $n^{\circ} 209$, Col. Barbier-Mueller n 521-36, Ginebra, Suiza, en Arte precolombino... 1994, pp. 276, Figura 79. Veánse colgantes de piedra verde de Guanacaste en Benson ed. 1981, pp. 150 y Soto Méndez 1996, pp. 99, cerámica de Nicaragua en Col. privada Alfonso Robelo n A.E 64 com. pers. Borgnino / Lauthelin, figurillas y colgantes de guanín del Diquís, 700-1000 d.C., en Benson ed. 1981, pp. 223 y Trésors... 1992, pp. 277.

30. Véase pieza $n^{\circ} 89$ en Trésors... 1964, pp. 144, Tesoros del Arte... 1971, pp. 21 y Ferrero 1987, Figura VIII-29, pp. 293.

31. Museo Nacional de Costa Rica ${ }^{\circ} 23175$, Ferrero 1987, Figura II-73, pp. 94.

32. Veánse representaciones de collares y colgantes del tipo Rosales en Reynoard Baumgarten 1996, Figura 22 o Papagajo en Centro America 1992, pp. 349, n० 198-199.

33. Charco negro sobre rojo en Abel Vidor 1990 , pp. 83 y Katz ed. 1985, pp. 75, Rosales en Snarskis 1982, pp. 26-27 y 29, Galo en Benson ed. 1981, pp. 46, Papagajo, Mora, Jicote en Centro America 1992, pp. 344$345, \mathrm{n}^{\circ} 171-174,189-191,198-200,205$ y $212, \ldots$

34. Pieza $n^{\circ} 308$, Col. privada Hernán Paez, com. pers. Borgnino / Lauthelin ; de otros tipos cerámicos indeterminados en Ferrero 1987, pp. 91 Figura 65 y Centro America 1992, pp. 345, $n^{\circ} 177$.

35. Museo de América, Madrid, en Paz Cabello Carro 1980, pp. 37, lám. VI.

36. Recipientes dobles o pares de cerámicas depositadas juntas. Pecaríes : pieza $n^{\circ} 313$, vasija doble, Col. privada A. Robelo, Nicaragua y piezas n $n^{\circ} 316 / 317$, Col. privada Oduber, Costa Rica. Pareja de músicos tocando maracas, antropo-zoomorfos, rostro de reptil, alas de murciélago (?), " hombre y mujer voladores" (véase infra) : piezas n ${ }^{\circ} 306 / 307$, Col. privada Oduber, Costa Rica. Com. Pers. Borgnino/ Lauthelin.

37. Piezas n $n^{\circ} 20 / 21$, Museo Nacional de Costa Rica n ${ }^{\circ} 23090 / 23927$ y n 308/309, Col. privada H. Paez $n^{\circ} 46 / 47$, Costa Rica, com. pers. Borgnino/Lauthelin ; pieza n $n^{\circ}$, Col. privada, Costa Rica, en Stone 1977, Figura 106, pp. 74 ; pieza 114, MNCR, n² 24067, en Ferrero 1987, pp. 124, Figura II-115. Véase también del tipo Cabuyal en Ferrero 1987, pp. 304, Figura VIJI-49.

38. Piezas $n^{\circ} 15,76-80,96,114,308 / 309,318, \ldots$ véanse referencias museológicas y bibliográficas, infra. Veánse Stone 1977, pp. 5S, Figura 63, Trésors.. 1992 Figura 235, Lothrop 1926, vol. II, Figura 137 y 163 y Centro America 1992, pp. 229.

39. Pieza n 58 col. privada, Costa Rica, en Baudez 1967, Figura 20, pp. 237. Carrillo en Benson ed. 1981, pp. 191, $n^{\circ} 81$, Jicote (?) en Katz ed. 1985, pp. 178.

40. Pieza $n^{\circ} 42$, " metate » en forma de cocodrilo de dos cabezas, Carnegie Museum, en Hartman 1907, pp. 20, Figura 13 y véase Stone 1977, pp. 74, Figura 117.

41. Cerámica bicroma zonada y objetos de piedra verde en Ferrero 1987 , pp. 69, Figura 125 y varias lám. ; la estatuaria sigue siendo difícil de fechar, véase Baudez et alii 1992, pp. 75-118.

42. El hecho de que las mejillas están representadas ahuecadas con pómulos salientes podría significar la realización de algún tipo de tratamiento postmortem. En efecto, durante el proceso natural de descomposición, las mejillas se hinchan y desforman hasta romperse.

43. Ferrero 1987, pp. 57 y 89 Figuras 114 y I-59 y Figura XVII, com. pers. V. Lauthelin y véanse Snarskis 1982, pp. 34, Ferrero 1987, pp. 75, 281 Figuras VIII-9/10, 294-295 y Trésors... 1992, pp. 257-258.

44. Huerta, Castillo, Papagayo en Centro America 1992, pp. 353, n²25, Birmania en Ferrero 1987 , pp. 292, Figura VIII-27, Jicote y Vallejo en Abel Vidor et alii 1990 , pp. $267-270$ y $280-282, \ldots$

45. Ocarinas de dos lóbulos : véanse piezas nº 136 y 137, Peabody Museum en Lothrop 1926, vol. II, lám. CXXX-h/i, pieza $n^{\circ} 145$, Musée de l'Homme, Paris, en Baudez 1967, pp. 345-E.

46. Piezas $n^{\circ} 231$, National Museum of the American Indian $n^{\circ} 23756$, N.Y, en Bransford 1881, pp. 43, Figura 105 (segundo derecha), Lothrop 1926, vol. II, lám. CVIIl-c y Vyckoff 1971 lám. B-izquierda, $n^{\circ} 232$, British Museum, Londres, en Joyce 1916 lám. IV-53, n² 233, U.S National Museum, Washington d.C., en Lothrop 1926, vol. II, pp. 235 Figura 123-b y n²34, N.M.A.I n 22385 , N.Y, en Bransford 1881, pp. 43, Figura 105-izquierda.

47. Pieza $n^{\circ} 91$, col. privada Herrera, Costa Rica, Figura $10 \mathrm{I}$, pieza $n^{\circ} 115$, Instituto Nacional de Seguros 2794, Costa Rica en Benson ed. 1981, pp. 187, Figura 59.

48. Tola en Tesoros.. 1971, pp. 97, Potosí en Tesoros... 1971, pp. 43 y Centro America 1992, pp. 341, $n^{\circ} 153$, de tipo indeterminado, sentado en un «metate » en Ferrero 1987, pp. 100 Figura 185. 
49. Piezas del tipo Marbella: $\mathrm{n}^{\circ}$ 142, Peabody Museum, Lothrop 1926, vol. Il, lám. CXXX-c, $\mathrm{n}^{\circ}$ 286, col. privada Anderson, E.E.U.U., Lothrop 1926, vol. II CXXX-b, n 292 y 294, Museum der Natur Historichen Gesellschaft, Nürnberg, Alemania, Lehman-Mūnchen 1913 lám. 26 (56 y 55a).

50. Piezas $n^{\circ} 213$, Museum für Völkerkunde IV ca 41307, Berlin, Figura 14 A y n ${ }^{\circ} 293$, Museum der Natur Historichen Gesellschaft, Nürnberg, Alemania, Lehman-München 1913 lám. 26 (55).

51. Pieza $n^{\circ} 186$, Museo Nacional de Costa Rica, $n^{\circ} 1510$ en Lothrop 1926, vol. II, pp. 232 Figura 119-a, $n^{\circ} 187$, Figura XV-C, n 192, col. A. Sackler en Katz ed. 1985, pp. 205, Figura 114.

52. Pieza n 306 : «mujer-voladora », col. privada Oduber, Costa Rica, com. pers. Borgnino/Lauthelin.

53. Bocana en Lothrop 1926, vol. II, Stone 1977, pp. 40, Figura 45 y Benson ed. 1981, Tola en Stone 1977, pp. 57, Figura 68 y Ferrero 1987, pp. 70, lám I-b, Carrillo en Ferrero 1987, pp. 81, Figura 146 [?] y tipos indeterminados en Benson ed. 1981, pp. 32 y Quesada López-Calleja 1980, pp. 175,...

54. Veánse Rosales en Reynoard Baumgarten 1996, Figura 22 y Papagajo en Centro America 1992, pp. 349, n 198-199 y Lothrop 1926, vol. II, Figura 139-d.

55. Galo y Carrillo en Tesoros... 1971, pp. 29, Ferrero 1987, pp. 294-295, Centro America 1992, pp. 347, $n^{\circ} 189$ y Soto Méndez 1996, pp. 46 ; Cabuyal, Mora y Papagayo en Lothrop 1926, vol. I, lám. LXXX-LXXXI y Figura 74-a/b y Katz ed. 1985.

56. Objetos de piedra verde del Atlántico Costarricense (anteriores al 800 d.C.) y pendientes de tumbaga de la Gran Chiriquí (700-1550 d.C.) en Centro America 1992, pp. 363/366 n 286/299-300, cerámica policroma coclé del Panamá central (600-1200 d.C.) y cerámicas taironas de Colombia (900-1550 d.C.) en Trésors... 1992, pp. 281/318.

57. Pectoral y pendientes de tumbaga del sur de Costa Rica (700-1000 d.C.) en Benson ed. 1981, pp. 233, n 264-265 y en Trésors.. 1992, pp. 277.

58. Pendientes de tumbaga de Coclé (800-1200 d.C.) en Trésors... 1992, pp. 284, de la Gran Chiriquí (700-1550 d.C.) en Centro America 1992, pp. 33, $\mathrm{n}^{\circ} 344$ y sinú de Colombia (900-1550 d.C.) en Trésors... 1992, pp. 328.

59. Veánse figurillas femeninas de piedra (1000-1550 d.C.) en Graham 1981, representaciones de metates en cerámicas taironas de Colombia y de Trujillo, oeste de Venezuela, en Trésors.. 1992, pp. 304 / 317, cabezas antropomorfas « cadavéricas " y animales en Ferrero 1987 para Costa Rica y en catálogos ya citados para otras regiones istmeñas (véasesupra).

60. Veánse piezas olmecas, mayas y de Teotihuacán en Ferrero 1987, pp. 63/87 y lám. XLI-XLVI y Quesada López-Calleja 1980, pp. 99-114.

61. Para una descripción detallada de los conocimientos sobre las influencias mesoamericanas directas e indirectas en la Gran Nicoya, véanse Day 1984, pp. 15-195, Fowler 1989 o Constenla Umaña 1994,...

62. El lugar actual de conservación no pudo ser verificado para cada pieza estudiada. Se dan las más recientes referencias disponibles. Algunas piezas publicadas no pudieron ser atribuidas a una colección en particular ; en ese caso estan presentadas bajo la denominacion "Colección indeterminada" con sus referencias bibliográficas.

63. Véase Lothrop 1926, vol. II.

64. Veánse L'art précolombien du Panama... 1978 y Ferrero 1987.

65. Véase Joyce 1916.

66. Véase Hartman 1907.

67. Véase Stone 1958.

68. Véase Lothrop 1926 vol. II.

69. Véase Ferrero 1987.

70. Véase Arte Precolombino... 1994.

71. Véase Ferrero 1987.

72. Veánse Baudez 1970 y com. pers. Borgnino / Lauthelin.

73. Véase Tesoros del arte... 1971.

74. Véase Day 1984.

75. Véase Tesoros del arte.. 1971.

76. Véase Tesoros del arte.. 1971.

77. Véase Tesoros del arte.. 1971.

78. Véase Stone 1977.

79. Com. pers. Borgnino/Lauthelin.

80. Véase Stone 1977. 
81. Com. pers. Borgnino / Lauthelin.

82. Véase Benson ed. 1981.

83. Com. pers. Borgnino / Lauthelin.

84. Véase Katz ed. 1985.

85. Véase Lange ed. 1988.

86. Veánse Quesada-López Calleja 1980, Benson ed. 1981, Snarskis 1982, Ferrero 1987, Centro America... 1992 y com. pers. Borgnino / Lauthelin.

87. Véase Paz Cabello 1980.

88. Véase Baudez 1967.

89. Véase Lehman-München 1913.

90. Véase Desrayaud 1996.

91. Véase Auto-portraits... 1995.

92. Véase Stone 1983.

93. Veánse Lothrop 1926, vol. II, Stone 1977, Quesada-López Calleja 1980, Benson ed. 1981, Ferrero 1987 y Borgnino / Lauthelin com. pers.

94. Veánse Bransford 1881, Lothrop 1926, vol. II y Wyckoff 1971

95. Veánse Lothrop 1926, vol. II, Stone 1972, 1976 y 1977.

96. Véase Federschlange... 1982.

97. Véase Parsons 1980.

98. Veánse Bransford 1881, Wilson 1896, Lothrop 1926, vol. II, Baudez 1967.

\section{BIBLIOGRAFÍA}

$\mathbf{P}$ (pieza cerámica) $+\mathbf{n}^{\circ}+$ referencias

ej : «Arte Precolombino...»-, 1994

P90, pp. $\mathbf{2 7 7 ( 8 0 )}=$ pieza $\mathrm{n}^{\circ} 90$, ref : página 277 Figura 80 de la obra citada

Abet. Vidor, S., Baudez, C. F., Bishop, R., Bonilla, V. L., Calvo M., M., Creamer, W., Day, J., Guerrero, J. V., Healy, P., Hoopes, J., Lange, F. W., Salgado, S., Stroessner, R. \& Tillet, A., 1990. - "Principales tipos cerámicos y variedades de la Gran Nicoya », I'́nculos, Revista del Museo Nacional de Costa Rica, vol. 13, n 1 \& 2, pp. 35-319. P9, pp. 69-D, P60, pp. 69(10-a), P97, pp. 83(12-a), P152, pp. 91(13-D), P174, pp. 23(25-D), P214, pp. 295(34-B), P217, pp. 239(26-A), P250, pp. 315(36).

Arte Precolombino en la colección Barbier-Mfueller, 1994. - Catálogo de la exposición organizada por el Musée Barbier-Mueller de Ginebra, Sociedad del Vo. Centenario del Tratado de Tordesillas, Casa de Colón, Colón s/n, Valladolid. P90, pp. 277(80), P209, pp. 276(79).

Autoportraits du Nouveau Monde. Collection Précolombienne. Musée d'Ethnographie de Genève, 1995. - Textos de D. Schoepf, fotos de F. Giona, Priuli \& Verlucca eds., Ivrea (Torino), Ediciones Olizane, Ginebra. P74, pp. 59(29).

Baudez, C. F., 1967. -- Recherches archéologiques dans la Vallée du Tempisque, Guanacaste, Costa Rica, Centre National de la Recherche Scientifique-I.H.E.A.L. Travaux et Mémoires $\mathrm{n}^{\circ}$ 18, Universidad de París. P4, pp. 335-F, P6-7, pp. 355-D/G, P44, pp. 355-B, P45, pp. 353A/B, P46, pp. 355-E, P58, pp. 237(20), P104, pp. 355-A, P105, pp. 353-F, P107-108, pp. 353D/E, P110, pp. 355-C, P111, pp. 353-G, P144-145-146, pp.345-A/E/D, P156-157-158, pp. 343-A/CID, P210, pp. 367-G, P219, pp. 36-E.

--, 1970. - Amérique Centrale, Colección Archaeologia Mundi, Ediciones Nagel, Ginebra. P170, pp. 245, P201, pp. 245(94). 
BAudez, C. F. \& COE, M. D., 1962. - « Archaeological sequences in northwestern Costa Rica 》, in : Actas del 34o. Congreso Internacional de Americanistas, pp. 366-373, Viena, Austria 1960.

Baudez, C. F., Borgnino, N., Laligant, S. \& Lauthelin, V., 1992. - Papagayo, un hameau précolombien du Costa Rica, Centro de Estudios Mexicanos y CentroAmericanos (México)Ediciones Recherche sur les Civilisations, París. P53-54-55 lám. 2-b/d/e, P221 lám. Cér. 9-b, P252-253 lám. 16-a/b.

Benson, E. P., (ed.), 1981. - Between Continents \& Between Seas : Precolumbian Art of Costa Rica, catálogo de exposición en asociación con el Detroit Institute of Arts, Harry N. Abrams Inc. Publishers, New York. P39, pp. 187(56), P115-116, pp. 187(59-60), P121122, pp. 188(61 izquierda/derecha), P149-150, pp. 178(3 arriba/abajo), P153-154, pp. 187(6263), P193, pp. 195(101), P254, pp. 198(113).

Bishop, R. L., 1994. - "Análisis de la composición de la cerámica en el sur de América Central ", Vínculos, Revista del Museo Nacional de Costa Rica, vol. 18 \& 19 (1992/93), pp. 9-30.

Bishop, R. L., Langh, F. W., Abel Vidor, S. \& Lange, P. C., 1992. - « Compositional characterization of the Nicaraguan ceramic sample ", in: The Archaeology of Pacific Nicaragua, pp. 135-162 (véaseLange F.W., Sheets P. et alii, 1992).

Bishop, R. L., LANGE, F. W. \& LANGe, P. C., 1988. - « Ceramic paste compositional patterns in Greater Nicoya pottery », in : Costa Rican Art and Archaeology : Essays in honor of $F . R$. Mayer, pp. 1-144 (véaseLange F.W., ed., 1988).

Borgnino, N. \& Lauthiflin, V. (com. personal), P36(Museo Nacional de Costa Rica 24634), P100-101(col. privadas), P161(MNCR 9343), P162(MNCR 15313), P163(MNCR 15309), P164(MNCR 9332), P172(MNCR 23910), P187(MNCR 27002), P200(MNCR ?), P262(MNCR 4200), P269(MNCR 1321), P298-299(MNCR 9305/21235), P304-305-306307-308-309(col. privadas), P310(Banco Central de Costa Rica 1580), P311(Instituto Nacional de Seguros 3294), P312-313-314-315-316-317-318-319-320-321-322(col, privadas), P323(MNCR 23381), P324-325(col. privadas), P326(MNCR 22511).

BRANSFORD J. F., M. D., 1881. - Archaeological Researches in Nicaragua, Smithsonian Contributions to Knowledge $n^{\circ} 383$, publicado por la Smithsonian Institution, Washington. P131, pp. 75(135 izquierda), P147, pp. 75(135 derecha), P226-227-228, pp. 44(arriba izquierda/arriba en el medio/arriba derecha), P231, pp. 43(105-segundo izquierda), P234, pp. 43(105 izquierda).

BraY, W., 1981. — «Gold Work », in : Between Continents \& Between Seas. Precolumbian Art of Costa Rica, pp. 152-166 (véase Benson, ed., 1981).

—, 1984. - " Across the Darien Gap : A Colombian view of Isthmian Archaeology ", in : Archaeology of Lower Central America, pp. 305-341 (véase Lange \& Stone, eds., 1994)

CARlsen, R. S., 1988. — « Preliminary investigations into the ceramic seals and roller stamps of Costa Rica ", in : Costa Rica Art and Archaeology..., pp. 189-201 (véase Lange ed., 1988).

Centro America. Tesori d'Arte delle Civilita Precolombiane, 1992. - Exposición bajo la dirección de Cavatrunci Claudio, Orefici Giusepe, Terenzi Claudia et alii, Fabri Editori, Milano. P290, pp. 350(206).

Cooke, R., 1993. - « Animal Icons and Pre-Columbian Society: The Felidae with Special Reference to Panama ", in : Reinterpreting the Prehistory of Central America, in : (véase Graham Miller ed., 1993).

Constenla Umaña, A., 1994. - « Las lenguas de la Gran Nicoya », Vinculos, Revista del Museo Nacional de Costa Rica, vol. 18 \& 19 (1992/93), pp. 191-208. 
DAY, J. S., 1982. - « Decorated Ceramic Types from the Late Polychrome Period, 1200-1550 A.D, Hacienda Tempisque, Guanacaste Province, Costa Rica ", V'inculos, Revista del Museo Nacional de Costa Rica, vol. $8 \mathrm{n}^{\circ} 1$ \& 2, pp. 39-65. P243, pp. 63(22).

-, 1984. - New Approaches in Stylistic Analysis: The Late Polychrome Period Ceramics from Hacienda Tempisque, Guanacaste Province, Costa Rica, PhD., University of Colorado (no publicado). P222, pp. 236(B-7), P241-242, pp. 345(B-27/26).

,$-- 1985 .-$ « Polychrome Ceramics and Iconography », in : Art of Costa Rica. Pre-Columbian Painted and Sculpted Ceramics from the Arthur M. Sackler Collections, pp. 39-50 (véase Katz Lois, ed., 1985).

Desrayaud, G., 1996. - Céramiques d'Amérique Centrale Méridionale, tesis de maestría, Universidad de París I (no publicado). P280, pp. 78.

Federschlange tund Konigsgeier Altindianische Kunst aus C. Rica, 1982.-Zusammengestellt und Bearbeited von Henning Bischof, Bildhefte des Stadt, Reiss Museum Mannheim, Volkerkundliche Sammlungen, N.R. 3. P52 Figura 4, P123 Figura 1, P244 Figura 15.

FErrero, L., 1987. -- Costa Rica Precolombina. Arqueología, Ethología, Tecnología, Arte, 5a. edición, Biblioteca Patria, Editorial Costa Rica, San José, Costa Rica. P10 lám. VII, P12 ilus. I-31, P17 lám. VI, P18 ilus. IV-8, P21 ilus. I-67, P38 ilus. I-32, P86, pp. 94(I-73), P89, pp. 293(III-29), P114, pp. 124(I-115), P134, pp. 71(I-30), P135 lám. II, P180-181 lám. VI(abajo derecha/izquierda), P245-246, pp. 106(I-96/97), P264, pp. 243(II-33).

FonseCA Zamora, Oscar M., 1993. - « Art, Ideology and Totality : Representational Art of Costa Rica's Central Region in the Late Period (A.D 1000-1500) », in : Reinterpreting the Prehistory' of Central America, pp. 103-140 (véase Graham Miller, ed., 1993).

—, 1994. - « El concepto de área chibchoide y su pertinencia para entender Gran Nicoya », Vínculos, Revista del Museo Nacional de Costa Rica, vol. 18 \& 19 (1992/93), pp. 209-228.

Fowler, W. R., 1989. - The Cultural Evolution of Ancient Nahua Civilization: The PipiNicarao of Central America, Univ. of Oklahoma Press, Norman, E.E.U.U.

Gorin, F., 1989. - Archéologie de Chontales, Nicaragua, vol. I \& II, thèse de nouveau doctorat, Universidad de París I Panthéon-Sorbonne, bajo la dirección del Dr. José Garanger (no publicado).

Graham Miller, M., 1981. - «Traditions of Costa Rican Stone Sculpture », in : Between Continents \& Between Seas : Precolumbian Art of Costa Rica, pp. 113-134 (véaseBenson ed., 1981).

—, 1993. - (ed.), Reinterpreting the Prehistory of Central America, University Press of Colorado, Niwot, Colorado, E.E.U.U.

GrzimeK, B., (ed.), 1974. — Le monde animal en treize volumes. Encyclopédie de la vie des bêtes, Ediciones Stauppaeher S.A., Zurich.

-, 1990. - Grzimek's Encyclopaedia of Mammals, primera edición en inglés (traducción de Enzyklopadie Sagtiere, 1988), Sybil Paker ed., Mc Graw-Hill Publishing Co.

Guerrero M., J.-V., 1986. - « Recientes investigaciones en el Valle de Nosará, Guanacaste », Journal of the Steward Anthropological Society 14 (1-2), pp. 171-189 (véase Lange F. W. \& Norr L. eds., 1986). P166-167-168-169, pp. 183(12.4-A/B/C/D).

Hartman, Carl V., 1907. - " Archaeological Researches on the Pacific Coast of Costa Rica », Memoirs of the Carnegie Museum, vol. III n ${ }^{\circ} 1$. W.J. Holland ed., Carnegie Institute, Pittsburgh, E.E.U.U. P42, pp. 20(13), P43, pp. 25(28), P126-127, pp. 27(40/39), P128, pp. 21(14), P129 lám. II-2, P143, pp. 27(38), P218, pp. 35(57), P273, pp. 36(61-62), P289, pp. 35(58). 
Healy, Paul F., 1980. - Archaeology of the Rivas Region, Nicaragua, Wilfried Laurier University Press, Waterloo, Ontario.

Holmis, William H., 1908. — « Book Review : Archaeological Researches on the Pacific Coast of Costa Rica by C.V. Hartman, 1907 ", American Anthropologist, New Series 10, pp. 128133.

Hoopes, John, 1984. - « Investigaciones arqueológicas en la cuenca de la Laguna de Arenal, Cordillera de Guanacaste, C. Rica », Vínculos, Revista del Museo Nacional de Costa Rica, vol. 10.

126 Auktion. Praekolumbische Kunst. Galerie Wolfgang Ketterer Munchen, 1988, - Sábado 25 de Junio 1988, Calle Brienner, Munich, Alemania. P68, pp. 83, P78, pp. 83(84).

JANZEN, D. H., 1983. - Costa Rican Natural History', The University of Chicago Press, Chicago, Illinois, E.E.U.U.

Joyce, Thomas A., 1916. - Central American and West Indian Archeology, Philip Lee Warner, 7 Grafton Street, W., Londres. P229 lám. IV-5, P232 lám. IV-3, P251 lám. IV-2.

Katz, Lois, (ed.), 1985. - Art of Costa Rica. Pre-Columbian Painted and Sculpted Ceramics from the Arthur M. Sackler Collections, The Arthur M. Sackler (A.M.S.) Foundation and the A.M.S. Foundation for the Arts, Sciences and Humanities for the Arts, Washington D.C. P14, pp. 82-83(15), P28, pp. 84-85(16), P34, pp. 89(19), P40, pp. 88(18), P41, pp. 86(17), P48, pp. 290(7), P75, pp. 79(12), P76, pp. 80(13), P155, pp. 17(3), P178, pp. 203(112), P179, pp. 202(111), P185, pp. 206(115), P192, pp. 205(114), P194, pp. 200(110), P202, pp. 204(113), P212, pp. 206(116), P220, pp. 207(117), P263, pp. 208209(118), P265, pp. 76-77(10), P270, pp. 198(108), P281, pp. 199(109).

Kennedy, E. E., 1981. — « Jade », in : Between Continents \& Between Seas : Precolumbian Art of Costa Rica, pp. 135-151 (véase Benson, ed., 1981).

LANGe, F. W., 1976. - «Bahías y Valles de la Costa de Guanacaste », Vinculos, Revista del Museo Nacional de Costa Rica, vol $2 \mathrm{n}^{\circ}$ 1, pp. 45-67. P240, pp. 57-A.

-, 1993. - «The Conceptual Structure in Lower Central American Studies : a Central American View », in : Reinterpreting the Prehistory of Central America, pp. 277-324 (véase Graham Miller M., ed., 1993). P81, pp. 309.

-, 1994. - « Evaluación histórica del concepto de Gran Nicoya. », Revista del Museo Nacional de Costa Rica, vol. 18 \& 19 (1992/93), pp. 45-67.

-, 1988. - (ed.) Costa Rican Art and Archaeology. Essays in Honor of Frederick R. Mayer, The Regents of the University of Colorado, Boulder, E.E.U.U. P11, pp. 334(36).

-, 1992. - Wealth and Hierarchy in the Intermediate Area, simposio en Dumbarton Oaks, 10 \& Il de octubre 1987, Dumbarton Oaks Research Library and Collection, Washington D.C.

Lange, F. W. \& Murray, T. A., 1977. — « Archaeology of the San Dimas Valley, Costa Rica », Katunob VII(4), pp. 50-91.

Lange, F. W. \& NorR, L., (eds.), 1986. - «Prehistoric settlement patterns in Costa Rica ", Journal of the Steward Anthropological Society 14 (1-2), 1982-83.

LANGe, F. W., R yDeR, P. \& ACCOLA, R. M., 1986. — « Bay of Culebra Survey », in : « Prehistoric settlement patterns in Costa Rica ", Journal of the Steward Anthropological Society' 14 (1-2), 1982-83, pp. 25-36 (véase Lange \& Norr, eds., 1986).

LANGE, F. W., SheEts, P. D., MARTinez, A., ABeL Vidor, S. et alii, 1992. — The Archaeology of Pacific Nicaragua, University of New Mexico Press, Albuquerque, E.E.U.U.

LANGE, F. W. \& Stone, D. Z., (eds.), 1984. - The Archaeology of Lower Central America, School of American Research Book, seminario, 8-14 de abril 1980 en Santa Fe, University of New Mexico Press, Albuquerque, E.E.U.U. P247, pp. 185(7.8). 
LAuTHeLIN, V., 2000. — Céramique polychrome sur engobe "saumon " de la Grande Nicoya, thèse de doctorat, Université de Paris I.

L'Art précolombien du Panama et du Costa Rica, 1978. - Catálogo de exposición en el Petit Palais, París, Nov. 1977-Feb. 1978. Adaptado del italiano (Exposición de Roma) por C. Join Deterle, Les Presses Artistiques, París. P59 Figura 153, P183-184 Figura 154/152.

Lehman-MÜNChen, WV., 1913. - « Die Archaologie Costa Rica 》, in : Festclrift zum XLIV Anthropologen Kongress, pp. 65-104, Nurnberg 1913. P8 lám. 26(53), P16 Jám. 26(54), P50 lám. 26, P291-292-293-294 lám. 26(57/56/55/55a).

LeIBSoHn, D., 1988. - « The Costa Rican effigy head tradition », in : Costa Rican Art and Archaeology. Essays in Honor of Frederick R. Mayer, pp. 131-160 (véaseLange F. W. ed., 1988).

LINES, J. A., 1934. - Catálogo descriptivo de los objetos expuestos en la primera Exposición de Arqueología y' Arte Precolombino inaugurada en Sam José de Costa Rica el 12 de Octubre de 1934 en el Teatro Nacional, Secretaría de Educación Pública, Imprenta Nacional, San José, Costa Rica. P84, pp. 75(110).

—, 1936. - Una huaca en Zapandi, Imprenta Lehman, San José, Costa Rica. P225, pp. 22(19).

Lothrop, S. K., 1926. - « Pottery of Costa Rica and Nicaragua ", vols. I \& II, Contributions from the New York Museum of the American Indian, Heye Foundation vols. VII \& VIII, Vreeland Press, Inc., New York. Vol, II : P1 lám. CXI-e, P5 lám. CXI-c, P22 lám, CIX-ala', P23 lám. CX-f, P24 lám. CVIII-b/b', P25-26 lám. CIX-e/f, P29-30-31-32 lám. CII-b/c/f/g, P37 lám. CX-e, P56-57 lám. CIII-c/d, P64 lám. CXXX-e, P67, pp. 265(156-c), P69 ?, P79 lám. CXXXI-a/a', P83, pp. 265(155-a), P85, pp. 271(163-b), P87-88, pp. 265(154-b/a), P94-95 lám. CIX-c/d, P96 lám. CIV-d/d', P98 lám. CXXXI-b/b', P106 lám, CII-a, P109 lám. CVIII-a, P117, pp. 267(157-c), P124-125, pp. 278(172-a/d), P130, pp. 278(172-b), P136-137138-139-140-141-142 lám. CXXX-h/i/j///m/c/d, P148, pp. 269(160-a), P159 lám. CX-d, P171 lám. CX-b, P173, pp. 235(123-c), P175 lám. CIV-b, P176, pp. 236(124), P177 lám. CIV-e, P186, pp. 232(119-a), P189-190-191 Jám. CIV-f/c/g, P195 lám. CIII-a/b, P198, pp. 234(122), P199, pp. 244(134), P203 Jám. CV-c, P204, pp. 235(123-a), P205-206, pp. 233(121-a/120), P208, pp. 233(121-b), P224 lám. CV-a, P233, pp. 235(123-b), P235 lám. CVIII-e, P237 lám. CXXIII-b, P271 lám. CIV-lı, P272 lám. CVII, P274, pp. 270(161-a), P275-276, pp. 278(172e/c), P277 lám. CX-a, P284 lám. CX-g, P286-287-288 lám. CXXX-b/f/g, P295 lám. CXXXIV-f, P297, pp. 253(143).

—, 1964. - « Las culturas indígenas prehispánicas de Nicaragua y de Costa Rica », El pez y la serpiente $\mathrm{n}^{\circ}$ 5, pp. 33-164, Enero 1964, Editorial « El Carmén », Managua, Nicaragua.

Museo del Jade, Instituto Nacional de Seguros, 1979. - Imprenta Instituto Nacional de Seguros, San José, Costa Rica.

Norweb, A. H., 1964. - «Ceramic Stratigraphy in Southwestern Nicaragua », in : Actas del 35o. Congreso Internacional de Americanistas en México, vol. I, pp. 551-561, 1962.

Oviedo y Valdes, G. F. de, 1959. - Historia General y Natural de las Indias, Biblioteca de Autores Españoles, Col. Rivadeneira, Ed. Atlas, Madrid.

Parsons, L. A., 1980. - Pre-Columbian Art. The Morton D. May and the Saint Louis Art Museum Collections, Icon Editions, Harper \& Row Publishers, New York. P47 Figura 337, P77 Figura 336-b, P160, pp. 218(335), P215 Figura 338.

Paz Carello Carro, M., 1980. - Desarrollo cultural en Costa Rica Precolombina. Con el catálogo de las piezas arquelógicas de Costa Rica del Museo de América, Ministerio de Cultura, Dirección General del Patrimonio Artístico, Archivos y Museos, Patronato Nacional de Museos, Madrid. P72, pp. 37(VI). 
Primer congreso de antropología y de la defensa del patrimonio cultural de América Central, 1976. - Del 30/06 al 06/07/1975 en San José de Costa Rica, Centro de Estudios Centroamericanos, Instituto de Investigaciones Sociales, Universidad de Costa Rica, San José.

Quesada Lopez-Calleja, R., 1980.-Costa Rica. La Frontera Sur de Mesoamérica, 2a. edición (Ia. 1975), editado por el Instituto Costarricense de Turismo, San José, Costa Rica. P112, pp. 171(XIX), P119, pp. 230, P267-268, pp. 171/179, P278, pp. 197, P282, pp. 193.

Reynoard Baumgarten, M., 1996. - El papel del jade en el proceso socio-cultural de las sociedades antiguas de Costa Rica, tésis de licenciatura, Univ. de Costa Rica, Facultad de Ciencias Sociales, Escuela de Antropología y Sociología (no publicado).

Skirboll, E. \& Creaner, W., 1984. - «Inter Regional Ties in Costa Rican Prehistory», simposio en el Carnegie Museum of Natural History, Pittsburgh, Abril 27 1983, B.A.R. International Series 226, Oxford, R.U.

SNARSKIS, M. J., 1982. - La cerámica precolombina en Costa Rica, Instituto Nacional de Seguros, San José, Costa Rica. P35, pp. 29, P49, pp. 31, P99, pp. 32, P188, pp. 76, P249, pp. 81, P261, pp. 81, P279, pp. 49.

Soto Mendez, L. Z., 1996. - Catálogo de Arte Precolombino Costarricense, del Museo del Jade, Lic. Marco Fidel Tristán C. del Instituto Nacional de Seguros, San José, Costa Rica.

SQuier, E. G., 1853. - Nicaragua, its people, scenery, momments, and the proposed interoceanic canal, D. Appleton \& $C^{\circ}$ Publishers, New York. P3/P65/P66, pp. 338.

Stone, D. Z., 1948. - «The basic cultures of Central America », in : Handbook of SouthAmerican Indians, vol. 4, The Circum-Caribbean Tribes, pp. 169-194, Steward J.H. ed., Smithsonian Institution Bureau of American Ethnology, bulletin 143, Washington.

-, 1958. - Introducción a la arqueología de Costa Rica, Museo Nacional, San José, Costa Rica. P113 Figura 11-a, P283 Figura 8-c.

-, 1962. - «The Talamancan Tribes of Costa Rica », Papers of the Peabody Museum of Archaeology and Ethnology, Harvard University, vol. XLIII $n^{\circ} 2$.

-, 1972. - Pre-Columbian Man Finds Central America, Peabody Museum Press, Harvard University, Cambridge, Massachusetts, E.E.U.U. P300-301-302-303, pp. 197(arriba izquierda/arriba derecha/abajo izquierda/abajo derecha).

-, 1976. - Arqueología de la América Central, traducción de «Pre-Columbian Man Finds Central America », traducido por Danilo A. Palma, Biblioteca Centroamericana de las Ciencias Sociales, Editorial Piedra Santa, Guatemala. P51, pp. 127(192), P151, pp. 89(127), P211, pp. 127(191).

-, 1977. - Pre-Coltumbian Man in Costa Rica, Peabody Museum Press, Peabody Museum of Archaeology and Ethnology, Harvard University, Cambridge, Massachusetts, E.E.U.U.P2, pp. 76(111), P19, pp. 50(53), P33, pp. 156(210), P61, pp. 55(62), P62-63, pp. 49(52 izquierda/derecha), P73, pp. 49, P80, pp. 75(109 izquierda), P82, pp. 50(54), P92, pp. 74(105), P102, pp. 35(34), P103, pp. 44-b, P120, pp. 211(285), P182, pp. 37(39), P196, pp. 75(101), P223, pp. 87(134), P248, pp. 82(128), P266, pp. 43(49), P296, pp. 89(f).

-, 1983. - « A Synthesis of Pre-Columbian Ceramics from Costa Rica », Indiana, vol. 8, pp. 201-222. P213 Figura 3-4.

SweEney, J. W., 1979. - Guanacaste, Costa Rica : An analysis of pre-columbian ceramics from the North West Coast, PhD. 1975, Universidad de Pennsylvania, Ann Arbor University Microfilms International, Michigan, E.E.U.U. P70, pp. 608(75-G), P165, pp. 607(74-D), P207, pp. 574(42 arriba), P216, pp. 608(75-F), P239, pp. 05(72-a), P255-256-257-258-259, pp. 606(73-D/E/F/G/H), P260, pp. 605(72-E). 
Tesoros del Arte Precolombino de Costa Rica, 1971. - Recopilación de las diferentes piezas del mes publicadas por la Asociación de Amigos del Museo de 1963 a 1971, Museo Nacional de Costa Rica, San José. P13, pp. 92, P20, pp. 96, P91, pp. 73, P93, pp. 55, P197, pp. 58, P285, pp. 32.

Trésors du Nouveau Monde, 1992. — Catálogo de la exposición en los Musées Royaux d'Art et d'Histoire de Bruxelles 15/09-27 / 12/1992, Lin y Emile Deletaille coordinadores. P15, pp. 262(233), P27, pp. 262(232).

Vazquez L., R., Lange, F. W., Hoopes, J. W., Fonseca Z., O., Gonzalez R., R., Arias, A. C., Bishop, R. T., Borgnino, N., Constenla U., A., Corrales U., F., Espinoza P., E., Fletchir, L. A., Gubrrero M., J. V., Lauthilin, V., Rigat, D., Salgado G., S. \& SALGado G., R., 1992. - " Hacia futuras investigaciones en Gran Nicoya 》, Vinculos, Revista del Museo Nacional de Costa Rica, vol. 18/19 (1992-1993), pp. 245-277.

VIRL, R., 1977. - Étude de la céramique Ulua-Yojoa Polychrome (Nord-ouest du Honduras). Essai d'analyse stylistique du Babilonia, tésis de doctorado, Universidad René Descartes, París, (no publicado).

WICKoff, L. L., 1971. - « A suggested Nicaraguan pottery sequence based on the Museum Collection ", Indian Notes \& Monographs 58, New York Museum of the American Indian, Heye Foundation, New York. P230 lám. B(derecha), P236 lám. B(centro), P238 lám. B(abajo).

WILSON, T., 1898. - «Prehistoric Art ; or, the Origin of Art as Manifested in the Works of Prehistoric Man ", Report of the U.S National Museum for the year ending June 30, 1896, pp. 325-664, under the direction of the Smithsonian Institution, Annual Report of the Board of Regents of the Smithsonian Institution, Washington. P118, pp. 621(270), P132133, pp. 615(263-264). 